\title{
STUDY ON THE CRYSTALLIZATION OF MULTIARM
}

STARS WITH A POLY(ETHYLENEIMINE) CORE AND

POLY( $\varepsilon$-CAPROLACTONE) ARMS OF DIFFERENT

\section{LENGTH}

\section{Angélica Díaz ${ }^{1}$, Anna Bacaicoa ${ }^{1}$, María Teresa Casas $^{1}$, Lourdes Franco $^{1}$, Angels Serra ${ }^{2}$, Jordi Puiggalí ${ }^{1 * *}$}

${ }^{1}$ Departament d'Enginyeria Química, Universitat Politècnica de Catalunya, Av. Diagonal 647, Barcelona E-08028, SPAIN

${ }^{2}$ Departament de Química Analítica $i$ Química Orgànica Universitat Rovira i Virgili. C. Marcel.li Domingo, s/n. Campus Sescelades 43007 Tarragona, SPAIN

Correspondence to: Jordi Puiggali (Phone: 34 934150656; E-mail: Jordi.Puiggali@upc.edu) 


\section{ABSTRACT}

Crystallization of multiarm star systems constituted by a core of poly(ethyleneimine) (PEI) and arms of poly( $\varepsilon$-caprolactone) (PCL) was studied by transmission electron microscopy, calorimetry and optical microscopy techniques. Three systems differing on the degree of polymerization of PCL were studied as well as binary mixtures constituted by systems differing on the length of PCL arms. Samples were able to crystallize from both diluted solutions and the melt state giving rise to well-formed lamellae and spherulites, respectively. Lamellae of samples with large PCL arms were highly regular and corresponded to elongated hexagonal crystals with an aspect ratio that decreased with the length of PCL arms.

A significant decrease on equilibrium melting temperatures, degree of crystallinity and glass transition temperature was detected for samples having short PCL arms. Crystallization kinetics was also highly influenced by the length of PCL arms, being both nucleation density and secondary nucleation constant increased as the length of PCL arms decreased. Crystallization of star mixtures having different PCL lengths was determined by the larger arms since they initiated the process and subsequently shorter arms were progressively incorporated. A thermal nucleation was characteristic of multiarm star mixtures due to the different crystallization temperature ranges of samples with large and short PCL arms, whereas samples with a homogeneous arm length rendered an athermal nucleation. 
Keywords: Multiarm stars, poly(e-caprolactone), poly(ethyleneimine), crystallization kinetics, lamellar crystals.

\section{INTRODUCTION}

The use of polymers having dendritic structures like hyperbranched or star-like topologies may lead to a significant improvement of mechanical properties of polymer matrices without affecting their thermomechanical behavior. ${ }^{1-4}$ These structures prevent also chain entanglement and consequently low viscosity formulations can be derived. ${ }^{5}$ For example, it has been reported that star branched poly( $\varepsilon$-caprolactone)s with a Boltorn core had a lower zero shear rate viscosity than linear polyesters with similar molecular weights. ${ }^{6}$

Star modifiers provide advantageous technological applications in different fields as for example the development of epoxy coatings. Interesting properties like low shrinkage can also be achieved by the use of hyperbranched structures. ${ }^{7,8}$ In addition, the use of arms with labile groups (e.g., the ester linkages of poly( $\varepsilon$-caprolactone)) may provide the capability to get thermally reworkable materials. ${ }^{1,9}$

Multiarm stars can be synthesized following the "core-first" approach that consist on a living polymerization of a monomer from a multifunctional core. ${ }^{10-12}$ Systems based on commercial poly(ethyleneimine) (PEI) (Lupasol $^{\mathrm{TM}}$ ) having poly( $\varepsilon$-caprolactone) (PCL) arms of different lengths (Figure 1a) can be easily prepared at a low cost. Previous studies demonstrated that arms with a degree of polymerization of only 10 could effectively reduce the formulation viscosity and maintain a final $T_{g}$ of the derived material higher than measured in matrices modified with the corresponding linear polyester. ${ }^{13,14}$ 
Control of the arm length is in general interesting to improve solubility of the multiarm modifier in the corresponding polymer matrix. This feature has for example a crucial influence in thermal curing processes which became decelerated when more soluble systems having short arms were employed. ${ }^{15}$ In addition, chain flexibility and hydrophobic character of PCL arms provided a good miscibility in most epoxy resins ${ }^{16,17}$ and an improvement of toughness through crazing and shear yielding mechanisms to absorb energy locally. ${ }^{18}$

The attachment of regular linear units to a fully amorphous dendritic core may enable a crystallization process that rendered semicrystalline materials. Nevertheless, a minimum length of the arms seems to be required since units close to the amorphous core may be unable to crystallize and even the presence of the core could make chain fold less tight. ${ }^{19}$ Star polymers having PCL arms showed a lower degree of crystallinity than linear PCL as a logical consequence of the steric restrictions imposed by dendritic or hyperbranched cores. $^{19}$ It was also found that the typical lamellar rearrangement of PCL was less pronounced in star polymers respect to the linear ones since amorphous cores constituted an obstacle to the molecular reordering and the lamellar thicknening process. Interestingly, equilibrium melting temperature was higher in star polymers due the reduccion of entropy and positional freedom of the melt caused by the presence of the hyperbranched cores. ${ }^{19}$ Nevertheless, a faster crystallization of star-branched PCL derivatives compared with linear PCL was found when arms were sufficiently long. In this case, the result was explained as a consequence of a cooperative chain mobility in the melt sate, suggesting a faster ordering of polymer chains to further crystallize. ${ }^{20}$ 
Star-branched PCL samples exhibited a greater tendency than linear polymers to form spherulites, being postulated that the amorphous material placed between lamellar crystals enhanced the divergence of crystals at lamellar branch points. ${ }^{21}$ Morphology of single crystals of multiarm polymers has been scarcely studied but in general lamellar structures were reported for systems based on nylon $6^{22}$ and PCL ${ }^{23}$ arms. However, these crystals were more irregular than those obtained from the linear analogues. Specifically, crystals of star-branched PCL derivatives were characterized by the presence of many irregular steps on the lateral crystal growth faces, which were related to the high fold surface free energy and the constrained character of the star-branched polymers. ${ }^{23}$ In the case of PCL derivatives it was also detected that the crystal aspect ratio decreased when the length of the arms was increased. This ratio was also significantly greater for linear polymers with respect to star-branched and increased with crystallization temperature as it was well established for polyethylene. $^{24}$ The capability to render well-defined lamellar structures has been interpreted as a exclusion of the central cores from the crystalline regions. These cores should be located at the lamellar surface and the bounded arms should be integrated in the derived lamellae (Figure 1b).

Another relevant point that has recently been evaluated concerns the influence of the number of arms of a multistar polymer on the crystal morphology. Thus, sugar alcohols like glycerol, erythritol and xylitol have been employed as initiators of the ring opening polymerization of $\varepsilon$-caprolactone to get multistar polymer with three, four and five arms of similar length, respectively. ${ }^{25}$ A decrease of both melting enthalpy and crystallization rate was observed as the number of PCL arms was increased. It was interpreted as a consequence of the limiting effect of the central core on the chain mobility. 
In this work we want to insist on the influence of the arm length on factors that determine the crystallization process like crystal morphology, nucleation density, crystal growth and secondary nucleation constant. Specifically, the system derived from commercial Lupasol and $\varepsilon$-caprolactone (PEI-PCL) has been considered. Furthermore, coexistence of multiarm systems having different PCL arm lengths could be usual and therefore it becomes important to evaluate the implications of heterogeneous multiarm systems on thermal properties and the crystallization process.

\section{EXPERIMENTAL SECTION}

\section{Materials}

Poly(ethyleneimine) (PEI) Lupasol ${ }^{\circledR}$ FG $(800 \mathrm{~g} / \mathrm{mol})$ was purchased from BASF and used without further purification. The $\left(\mathrm{NH}_{2} / \mathrm{NH} / \mathrm{N}\right)$ relationship of this polymer was reported to be $1 / 0.82 / 0.53$, which corresponds to an equivalent number of primary, secondary and tertiary amines of $0.010,8.37 \times 10^{-3}$, and $5.3 \times 10^{-3} \mathrm{eq} / \mathrm{g}$. $\varepsilon$-Caprolactone (Sigma-Aldrich) was distilled under vacuum, whereas tin (II) 2-ethylhexanoate (Sigma-Aldrich, 98\%) was used without further purification. For comparative purposes a linear PCL sample with $M_{n}$ of $11,400 \mathrm{~g} / \mathrm{mol}$ was synthesized by ring opening polymerization of $\varepsilon$-caprolactone.

Multiarm star PEI-PCL copolymers were synthesized as previously described. ${ }^{23}$ Basically, PEI and the appropriate amount of $\varepsilon$-caprolactone were placed at room temperature in a twonecked flask equipped with a magnetic stirrer and a gas inlet to fill the flask with argon. After addition of a small amount of tin (II) 2-ethylhexanoate (i.e., $0.3 \mathrm{mmol}$ respect to 0.625 mmol of PEI), the flask was immersed in an oil bath thermostatized at $130{ }^{\circ} \mathrm{C}$ during $48 \mathrm{~h}$. The crude product was subsequently dissolved in chloroform and the polymer was isolated 
by precipitation in methanol. Finally, the sample was recovered by filtration and dried at 45 ${ }^{\circ} \mathrm{C}$ under vacuum for two days.

Degree of polymerization of PCL arms was controlled by means of the feed ratio between $\varepsilon$-caprolactone monomer and the number of active NH groups. Specifically, ratios of 10, 30 and 50 were selected to get polymers with rather different arm lengths. These samples will be named with the acronym PEI-PCL $x$, where $x$ accounts for the degree of polymerization. Number average molecular weights were $20,000,42,400$ and $85,500 \mathrm{~g} / \mathrm{mol}$ as determined by ${ }^{1} \mathrm{H}$-NMR spectroscopy ${ }^{26}$ for PEI-PCL 10 (Figure 2), PEI-PCL 30 and PEI-PCL 50 samples, respectively. Spectroscopic data also revealed that experimental degrees of polymerization of PCL arms were 12, 26 and 53 (i.e., very close to those expected from the selected feed ratios).

Mixtures of star samples having two different arm lengths were obtained by slow evaporation of a chloroform solution containing equal weights of both selected multiarm polymers. Mixtures will be named with the acronym PEI-PCL $x / y$ where $x$ and $y$ indicate the caprolactone degrees of polymerization of the involved multiarm stars.

\section{Measurements}

The spherulite growth rate was determined by optical microscopy using a Zeiss Axioskop 40 Pol light polarizing microscope equipped with a Linkam temperature control system configured by a THMS 600 heating and freezing stage connected to a LNP 94 liquid nitrogen cooling system. Spherulites were grown from homogeneous thin films prepared from the melt. Next, small sections of these films were pressed or smeared between two cover slides and inserted into the hot stage, giving rise to samples with thicknesses close to $10 \mu \mathrm{m}$ in all cases. Samples were kept at approximately $20^{\circ} \mathrm{C}$ above the polymer melting 
point for 5 minutes to eliminate sample history effects (when mixtures were studied the final temperature was determined from the component with the greatest melting temperature). For isothermal crystallization experiments, samples were quickly cooled to the selected crystallization temperature. The radius of growing spherulites was monitored during crystallization with micrographs taken with a Zeiss AxiosCam MRC5 digital camera at appropriate time intervals. A first-order red tint plate was employed to determine the sign of spherulite birefringence under crossed polarizers.

A Philips TECNAI 10 electron microscope was used and operated at $100 \mathrm{kV}$ and $80 \mathrm{kV}$ for bright field and electron diffraction modes, respectively. Selected area electron diffraction patterns were taken with a SIS MegaView II digital camera and internally calibrated with gold $\left(\mathrm{d}_{111}=0.235 \mathrm{~nm}\right)$.

Calorimetric data were obtained by differential scanning calorimetry with a TA Instruments Q100 series equipped with a refrigerated cooling system (RCS) operating at temperatures from $-90{ }^{\circ} \mathrm{C}$ to $550{ }^{\circ} \mathrm{C}$. Experiments were conducted under a flow of dry nitrogen with a sample weight of approximately $5 \mathrm{mg}$ and calibration was performed with indium. $T_{\text {zero }}$ technology required a calibration based on two experiments: the first was performed without samples while sapphire disks were used in the second. Thermal characterization was performed following a four run protocol consisting on a heating run $\left(20^{\circ} \mathrm{C} / \mathrm{min}\right)$ of the multiarm polymer, a cooling run $\left(10^{\circ} \mathrm{C} / \mathrm{min}\right)$ after keeping the sample in the melt state for three minutes to wipe out the thermal history, a subsequent heating run $\left(20^{\circ} \mathrm{C} / \mathrm{min}\right)$ of the sample crystallized from the melt and finally a heating run $\left(20^{\circ} \mathrm{C} / \mathrm{min}\right)$ of a sample quenched from the melt by immersion in liquid nitrogen. Isothermal crystallization studies were performed with samples previously heated $\left(20^{\circ} \mathrm{C} / \mathrm{min}\right)$ up to $25^{\circ} \mathrm{C}$ above their 
melting temperature (in the case of mixtures this was determined by the component with the highest melting point), subsequently held for $5 \mathrm{~min}$ at this temperature and finally cooled to the selected temperature at a rate of $50{ }^{\circ} \mathrm{C} / \mathrm{min}$. Samples were kept at the isothermal temperature until baseline was attained.

\section{RESULTS AND DISCUSSION}

\section{Thermal properties of PEI-PCL $\boldsymbol{x}$ multiarm stars}

DSC scans performed with samples having the shortest and the largest PCL arms are given in Figure 3 as representative examples, whereas properties determined for the three PEIPCL $x$ samples are summarized in Table 1. The most distinctive behaviour with respect to linear PCL was logically found for PEI-PCL 10. Thus, a double melting peak near 43 and $49^{\circ} \mathrm{C}$ was determined for the multiarm star (quenched sample) in contrast with the single peak reported for PCL within the $59-64{ }^{\circ} \mathrm{C}$ range (e.g. inset of Figure $3 \mathrm{~b}$ that shows a characteristic DSC trace for a representative PCL sample). The appearance of the double peak changed with the crystallization process and specifically the relative intensity of the lower temperature peak increased in the order solution crystallized > melt crystallized > quenched sample as expected from a typical lamellar thickening process (i.e., $48-49^{\circ} \mathrm{C}$ is associated with lamellae that are reordered/thickened during the heating process). Melting enthalpies indicated a degree of crystallinity of 56.7\% for the PEI-PCL 10 melt crystallized sample that was significantly lower than the value determined for PEI-PCL 50 (i.e., 67.1\%). Crystallinities were estimated taking into account the enthalpy of $135 \mathrm{~J} / \mathrm{g}$ that was reported for a $100 \%$ PCL crystalline sample ${ }^{27,28}$ and also the contribution of the PEI core to the total weight of the sample (i.e., 4\% and 1\% for PEI-PCL 10 and PEI-PCL 50, respectively). Crystallinities of the stars were nevertheless similar to the value close to $60 \%$ that was 
reported for PCL. ${ }^{29}$ It is interesting to note that the PEI-PCL 50 sample had the highest crystallinity, a feature that suggests an enhanced crystallization process that could be a consequence of the cooperative chain mobility of the multiarm system. ${ }^{20}$ Glass transition temperatures were between -62 and $-57^{\circ} \mathrm{C}$, decreasing as the PCL arms became shorter and in any case comparable with the typical value given for linear PCL $\left(-60^{\circ} \mathrm{C}\right)$.

\section{Equilibrium melting temperature of PEI-PLC $x$ multiarm stars}

Equilibrium melting temperature $\left(T_{m}{ }^{0}\right)$ is a crucial parameter for determining crystal growth rate and specifically degree of supercooling $\left(T_{m}{ }^{0}-T_{c}\right)$. The Hoffman-Weeks extrapolation ${ }^{30}$ is a commonly accepted method to estimate the equilibrium temperature due to its simplicity and straightforward implementation, although it is subject to criticism ${ }^{31}$ and improvements have been proposed. ${ }^{32}$ The method is based on equation 1, which was deduced from a combination of the well-known Gibbs-Thomson equation and secondary nucleation theory. ${ }^{33}$ This equation relates the melting temperature, $T_{m}$, of a crystal formed at a temperature $T_{c}$, the equilibrium melting temperature and the thickening coefficient, $\gamma$, defined as the ratio between the thickness of the grown crystal, $l_{c}$, and the initial thickness of a "virgin lamella", $l_{g}^{*}$ :

$$
T_{m}=T_{m}{ }^{0}(1-1 / \gamma)+T_{c} / \gamma
$$

A straight line is obtained by plotting $T_{m}$ as a function of $T_{c}$, with the equilibrium temperature corresponding to the intersection of this line with the $T_{m}=T_{c}$ line. The validity of equation 1 implies that lamellar crystals thicken at a specific crystallization temperature which also influences the thickening parameter. 
Figure 4 shows as a single melting peak was detected for the three types of multiarm stars, even for the PEI-PCL 10 sample, and that the melting temperature increased as the crystallization temperature did. An unambiguous estimation of an equilibrium melting temperatures could therefore be deduced from the Hoffman-Weeks plots (Figure 5). Equilibrium melting temperatures increased with the length of the PCL arms, being determined values of $58.4,73.1$ and $74.7{ }^{\circ} \mathrm{C}$. These values were larger than those determined for linear PCL samples having similar molecular weights (i.e., 45, 57, 64 and $67{ }^{\circ} \mathrm{C}$ were estimated for samples having molecular weights of 578, 1,750, 6,590 and $15,700 \mathrm{~g} / \mathrm{mol}$, respectively ${ }^{34}$ ) as expected from the above indicated decrease of the melting entropy for hyperbranched cores. ${ }^{16}$

It is also worth pointing out that the slope of the plots, $1 / \gamma$, can be regarded as a measure of the stability of crystals undergoing the melting process and that significant differences are found. Thus, short PCL arms clearly decreased the slope, suggesting a greater difference between $l_{c}$ and $l_{g}^{*}$.

\section{Lamellar and spherulitic morphologies of PEI-PCL $\boldsymbol{x}$ multiarm stars}

Typical poly( $\varepsilon$-caprolactone) lamellar crystals were obtained from PEI-PCL 30 and PEIPCL 50 multiarm star samples (Figures $6 \mathrm{~b}$ and 6c) by isothermal crystallization at 40-60 ${ }^{\circ} \mathrm{C}$ from dilute solutions in $n$-hexanol. In general, multilayered crystals were developed from helicoidal dislocations, being the thickness of individual lamellae close to $10 \mathrm{~nm}$ as determined by measuring their shadows in the electron micrographs. Morphology of crystals corresponded to truncated rhombic crystals with different aspect ratios depending on the sample and the crystallization temperature. Highly irregular crystals were obtained by contrast at the lower crystallization temperature $\left(40^{\circ} \mathrm{C}\right)$ from the sample with the 
shortest PCL arms (i.e., PEI-PCL 10). These had a lanceolate appearance, irregular edges and frequent striations on their surface (Figure 6b). In fact, multifacets seem to be developed on the curved faces as was also reported for other multiarm systems having in this case long PCL arms and a core consisting on a third-generation hyperbranched polyester with approximately 32 terminal hydroxyl groups (Boltorn, Perstorp AB, Sweden). ${ }^{23}$ Surface striations is a common feature of linear PCL crystals (e.g. Figure 6a) that have received different explanations (e.g., presence of microcrystals along the crystal growth direction ${ }^{35}$ or non-planar structure of crystals $^{36}$ ) but remains nowadays non completely understood. In any case, results clearly demonstrated the ability to crystallize of the star samples despite the relatively high bulk dimensions of the core and even the short length of crystallizable arms (i.e., PEI-PCL 10).

The electron diffraction patterns of PEI-PCL $x$ lamellar crystals are practically identical, being mainly characterized by four strong spots at spacings of $0.414 \mathrm{~nm}$ and two strong spots at $0.374 \mathrm{~nm}$ (Figure 7). These are indexed as the (110), (110) and (200) reflections of a rectangular unit cell with $a=0.747 \mathrm{~nm}, b=0.498 \mathrm{~nm}$. Patterns showed reflections up to $0.186 \mathrm{~nm}$ and systematic absences only for $h 00$ and $0 k 0$ reflections with $h$ or $k$ odd. These data are fully consistent with the reported structure of PCL that obeys to a $P 2_{1}{ }_{1} 2_{1}{ }_{1}$ orthorhombic space group with cell dimensions of $a=0.747 \mathrm{~nm}, b=0.498 \mathrm{~nm}$ and $c$ (fibre axis) $=1.705 \mathrm{~nm}$. The crystalline structure of PCL was reported to be an arrangement of molecules with a practically all trans molecular conformation. ${ }^{37-39}$

Correlation between bright field micrographs and the electron diffraction patterns showed that the crystallographic $b$ axis (or the reciprocal $\mathrm{b}^{*}$ axis) was parallel to the truncated face or the elongation direction of PEI-PCL 10 crystals. Therefore, the well-formed and 
truncated rhombic crystals were constituted by four $\{110\}$ faces and two $\{100\}$ faces, being the angles between two consecutive $\{110\}$ faces and between $\{110\}$ and $\{100\}$ faces of $112^{\circ}$ and $124^{\circ}$. Namely, very close to the theoretical values (i.e., those deduced from unit cell dimensions) of $113^{\circ}$ and $124^{\circ}$, respectively. It is well known that crystallization temperature influences the morphology of polyester single crystals, being characteristic an increase of the aspect ratio with crystallization temperature. ${ }^{40-42}$ This feature is not observed when truncated PEI-PCL 30 and PEI-PCL 50 crystals are compared since the aspect ratio (i.e., determined by the ratio of the dimensions of $\{100\}$ and $\{110\}$ faces) decreased from 3.5 to 1.7 despite the crystallization temperature was higher for the second sample $\left(60^{\circ} \mathrm{C}\right.$ respect to $40{ }^{\circ} \mathrm{C}$ ). It seems that the aspect ratio decreased also when the size of PCL arms increased $^{20}$ as can also be inferred when morphologies of PEI-PCL 10 and PEI-PCL 30 crystals obtained at the same temperature are compared. For the sake of completeness single crystals of linear PCL crystallized at $40{ }^{\circ} \mathrm{C}$ are shown in Figure 6a. Note that the aspect ratio (i.e. 2.1) becomes lower than those determined for star samples crystallized also at $40^{\circ} \mathrm{C}$.

PEI-PCL samples easily crystallized from the melt rendering typical spherulitic morphologies with a negative birefringence as depicted in Figure 8. Main differences concern to nucleation, which as will further discussed, is lower for samples having larger arms and a lower ratio of PEI cores that could act as primary nucleating agents.

\section{Isothermal crystallization analysis of PEI-PCL $x$ multiarm stars}

Kinetic analysis of multiarm polymers was only performed for melt crystallization processes because of the impossibility to obtain amorphous samples by cooling the melted polymer at the maximum rate allowed by the equipment. 
Crystallization experiments were therefore carried out in narrow temperature intervals due to experimental limitations. These covered the range between 28 and $37{ }^{\circ} \mathrm{C}$ for samples having the shortest PCL arms (i.e., PEI-PCL 10) and the ranges between 40 and 48 or $49{ }^{\circ} \mathrm{C}$ for PEI-PCL 30 or PEI-PCL 50 samples, respectively. The time evolution of the relative degree of crystallinity, $\chi(t)$, was determined from crystallization exotherms (e.g., Figure 9a for PEI-PCL 10) through the ratio area of the exotherm up to time $t$ divided by the total exotherm area:

$$
\chi(t)=\int_{t 0}^{t}(d H / d t) d t / \int_{t 0}^{\infty}(d H / d t) d t
$$

where $\mathrm{d} H / \mathrm{d} t$ is the heat flow rate and $t_{0}$ the induction time. The development of crystallinity always showed a characteristic sigmoidal dependence on time for the five melt crystallization experiments performed for the different samples (e.g. Figure 9b for PEI-PCL 10). These data were analyzed assuming the well-known Avrami equation ${ }^{43,44}$ for primary crystallization:

$$
1-\chi\left(t-t_{0}\right)=\exp \left[-Z\left(t-t_{0}\right)^{n}\right]
$$

where $Z$ is the temperature-dependent rate constant and $n$ the Avrami exponent whose value varies according to the crystallization mechanism. A normalized rate constant, $k=Z^{1 / n}$, is usually evaluated for comparison purposes since its dimension $\left(\right.$ time $\left.^{-1}\right)$ is independent of the value of the Avrami exponent.

Table 2 summarizes the main kinetic parameters of the primary crystallization process, as deduced from the plots of $\log \left\{-\ln \left[1-\chi\left(t-t_{0}\right)\right]\right\}$ against $\log \left(t-t_{0}\right)$ (Figure 9c). The values of the Avrami exponent for PEI-PCL 10 remained in a narrow range, from 2.19 to $2.47,2.37$ being the average value. This suggests the occurrence of predetermined (heterogeneous) 
nucleation with spherical growth under high geometric constraints since the theoretical value should be equal to 3 . Both sporadic (heterogeneous) and homogeneous nucleation can be clearly discarded as a higher exponent, close to 4 , should be derived. Furthermore, homogeneous nucleation usually requires high undercooling, which is not the case. It can be indicated that the Avrami exponents tended to decrease with decreasing the crystallization temperature, suggesting a higher geometrical constrain. Specifically, at a temperature of $28^{\circ} \mathrm{C}$ crystallization approaches to a two-dimensional growth. Samples with longer arms showed a similar behaviour, being the average Avrami exponents of 2.22 and 2.23 for PEI-PCL 30 or PEI-PCL 50 samples. Exponents of these samples were found to vary without a well-defined trend within slightly larger intervals (i.e., 1.60-2.48 and 1.812.64 for lengths of 30 and 50, respectively).

The values corresponding to reciprocal crystallization half-times $\left(1 / \tau_{1 / 2}\right)$, calculated as the inverse of the difference between crystallization start time and half-crystallization time, are also given in Table 2. This parameter is a direct measure of the crystallization process, and can therefore be used to check the accuracy of Avrami analysis by comparison with the theoretical kinetic value (i.e., $\left.1 / \tau_{1 / 2}=(Z / \ln 2)^{1 / n}\right)$. Values reported in Table 1 showed a good agreement between reciprocal crystallization half-times deduced from both methods. Summarized data allow also evaluating the variation of the overall rate constant with temperature for the different samples, as then will be discussed.

\section{Secondary nucleation constant for the isothermal crystallization of PEI-PCL $x$ multiarm stars}


Crystallization kinetics from the melt state was also studied for the three PEI-PCL $x$ samples by optical microscopy. Spherulite radii grew linearly in all cases with time until impingement, as shown in Figure 10a for the representative and less crystalline PEI-PCL 10 sample. Figure $10 \mathrm{~b}$ compares the temperature dependence of the crystal growth rate for the three PEI-PCL samples, being found a similar evolution than the overall crystallization rate $\left(k=Z^{1 / n}\right)$ determined from DSC experiments. The relatively high growth rate allowed collecting only experimental data over a narrow temperature range where crystallization was mainly governed by secondary nucleation. This interval was clearly shifted to lower temperatures for the sample with shorter arms but corresponded to a similar degree of supercooling (i.e., higher than $8^{\circ} \mathrm{C}$ ) than found for samples with larger arms (i.e., higher than $\left.13{ }^{\circ} \mathrm{C}\right)$.

Final spherulitic radii varied between 17 and $200 \mu \mathrm{m}$ and logically decreased for a given multiarm sample when primary nucleation density was higher (i.e., samples obtained at lower crystallization temperatures). Nucleation was very low at the highest crystallization temperature where spherulites with diameters up to $200 \mu \mathrm{m}$ could be obtained. The number of nuclei remained practically constant during crystallization for all isothermal experiments, suggesting that it proceeded according to an athermal nucleation. This feature can justify the observed proportionality between $G$ and $k$ as reported for different authors. ${ }^{45-}$ ${ }^{48}$ As can be seen in Figure 11a, the temperature evolution of primary nucleation revealed a single exponential dependence. It is remarkable that the number of active nuclei was high (e.g., 4,000 nuclei/ $/ \mathrm{mm}^{2}$ for the less crystalline PEI-PCL 10 sample crystallized at a such low temperature as $28^{\circ} \mathrm{C}$ ). This feature is a clear indication of the effectiveness of cores to start crystallization. In fact, PCL branches emanting from the core should be close enough 
and probably in a parallel array to start effectively the crystallization process. The maximum measured nuclei density varied also with the arm length, being found that this density decreased when stars had longer arms probably as a consequence of their lower ratio of PEI cores that may act as primary nuclei.

The radial growth rate $(G)$ of polymer crystals is usually described by the Lauritzen and Hoffman equation, ${ }^{49}$ which is based on the Turnbull-Fisher expression ${ }^{50}$ suitable for the crystallization process of homopolymers. The Lauritzen and Hoffman equation is formulated as:

$$
G=G_{0} \exp \left[-U^{*} /\left(R\left(T_{\mathrm{c}}-T_{\infty}\right)\right)\right] \exp \left[-K_{\mathrm{g}} /\left(T_{\mathrm{c}}(\Delta T) f\right)\right]
$$

where $G_{0}$ is a constant preexponential factor, $U^{*}$ represents the activation energy characteristic of the transport of the crystallizing segments across the liquid-crystal interface, $T_{\infty}$ is the temperature below which such motion ceases, $T_{\mathrm{c}}$ is the crystallization temperature, $R$ is the gas constant, $K_{\mathrm{g}}$ is the secondary nucleation constant, $\Delta T$ is the degree of supercooling measured as $T_{\mathrm{m}}{ }^{0}-T_{\mathrm{c}}$, and $f$ is a correction factor accounting for the variation in the bulk melting enthalpy per unit volume with temperature $\left(f=2 T_{\mathrm{c}} /\left(T_{\mathrm{m}}{ }^{0}+T_{\mathrm{c}}\right)\right)$.

It is advisable to rearrange Eq. (4) in a logarithmic form:

$$
\ln G+U^{*} / R\left(T_{\mathrm{c}}-T_{\infty}\right)=\ln G_{0}-K_{\mathrm{g}} /\left[T_{\mathrm{c}}(\Delta T) f\right]
$$

and plot the left-hand side of the equation versus $1 /\left[T_{\mathrm{c}}(\Delta T) f\right]$. Straight lines with slopes equal to $-K_{\mathrm{g}}$ should be obtained.

The Lauritzen-Hoffman plot was fitted for the three considered PEI-PCL $x$ copolymers with straight lines $\left(r^{2}>0.98\right)$ when the "universal" values reported by Suzuki and Kovacs ${ }^{51}$ (i.e., 
$U^{*}=1500 \mathrm{cal} / \mathrm{mol}$ and $T_{\infty}=T_{g}-30 \mathrm{~K}$ ) were used in the calculation (Figure $11 \mathrm{~b}$ ). Kinetic features at low supercoolings are basically governed by the nucleation term, and consequently crystallization rates could become relatively insensitive to the $U^{*}$ and $T_{\infty}$ parameters. The plot was used to estimate secondary nucleation constants of $0.66 \times 10^{5}$, $0.51 \times 10^{5}$ and $0.26 \times 10^{5} \mathrm{~K}^{2}$ for PEI-PCL 10, PEI-PCL 30 and PEI-PCL 50 samples, respectively. These values clearly indicate a greater difficulty for crystallization as the length of the PCL arm decreased.

\section{Thermal behavior of PEI-PLC $x / y$ multiarm star mixtures}

Figure 12 shows the calorimetric runs performed with the PEI-PCL 10/50 mixture as a sample having the largest difference between the lengths of constitutive PCL arms. Several points deserve attention when runs are compared with those obtained from each multistar system:

a) Melting point of the mixture becomes similar to that determined for the individual PEIPCL 50 component, indicating that shortest PCL arms were mainly incorporated into lamellae constituted by the sample with the larger arms. Namely, the characteristic crystals observed for PEI-PCL 10 (predominant melting peak at $44.8^{\circ} \mathrm{C}$ ) were not developed since only a very small shoulder could be detected near $49^{\circ} \mathrm{C}$.

b) Crystals became less perfect since a population of thin crystals were detected for solution crystallized samples in disagreement with results attained with PEI-PCL 50 (i.e., melting peaks at 58.1 and $61.3{ }^{\circ} \mathrm{C}$ were observed for the mixture in contrast with the single peak at $62.4^{\circ} \mathrm{C}$ observed for PEI-PCL 50). 
c) A complex melting peak was observed for melt crystallized or quenched samples, being temperatures again similar to those determined for PEI-PCL 50 crystals prepared under identical procedures.

d) Melting and crystallization enthalpies were lower than measured for the individual PEIPCL 10 and PEI-PCL 50 components and obviously than expected from a simple mixture of spherulites, a feature that it is again in agreement with an effective incorporation of short PCL arms into lamellae of the PEI-PCL 50 sample. Note for example that melting enthalpy of melt crystallized PEI-PCL 10/50 mixture is $74.1 \mathrm{~J} / \mathrm{g}$ (once the experimental enthalpy was corrected taking into account the mass of the PEI core), whereas a value of $83.6 \mathrm{~J} / \mathrm{g}$ could be expected for the mixture (i.e., the average of 76.6 and $90.5 \mathrm{~J} / \mathrm{g}$ enthalpies determined for the individual components).

e) Crystallization of PEI/PCL 10/50 from the melt was slightly delayed with respect to PEI/PCL 50 (i.e., 28.1 with respect to $32.7^{\circ} \mathrm{C}$ ) but took place clearly faster than PEI-PCL 10 (i.e., 28.1 with respect to $19.5^{\circ} \mathrm{C}$ ).

f) Glass transition temperature of the mixture became on the contrary closer to that observed for PEI-PCL 10 suggesting that the amorphous phase was enriched on the shortest PCL arms.

Figure 13 shows the equilibrium melting points determined for PEI-PCL 10/50, 30/50 and 30/50 mixtures according to the Hoffmann-Weeks plot. ${ }^{30}$ Values were similar (65.2-67.6 ${ }^{\circ} \mathrm{C}$ ) but slightly decreased as the average length of PCL arms did (i.e., the order of $T_{m}{ }^{0}$ values was PEI-PCL 30/50 > PEI-PCL 10/50 > PEI-PCL 10/30). It should be pointed out that these temperatures demonstrated again a worse degree of lamellar perfection than found for samples with larger PCL arms (i.e., PEI-PCL 50 and PEI-PCL 30 with 
temperatures higher than $73{ }^{\circ} \mathrm{C}$ ). Nevertheless, temperatures were significantly greater than detected for PEI-PCL 10 (i.e., $58.4^{\circ} \mathrm{C}$ ) as presumably for a crystallization driven by the largest PCL arms.

Crystallization from the melt gave rise to typical spherulites with a negative birefringence. Morphology of spherulites obtained at a given temperature was similar but with a wide range of diameter sizes for PEI-PCL 10/50 and PEI-PCL 10/30 samples (Figure 14). In fact, the number of nuclei increased during crystallization for all isothermal experiments, suggesting a thermal nucleation that could be related to the great difference between maximum temperatures at which crystallization of PEI-PCL 10 and PEI-PCL-30 or PEIPCL 50 multiarm samples is possible (Figure 10b).

\section{Influence of the coexistence of different PCL arm lengths on spherulitic growth rates, primary nucleation density and secondary nucleation constant}

Figure 15a shows the evolution of the crystal growth rate for the different studied multiarm mixtures. Measurements could be performed in different temperature intervals but in this case the highest temperature was always similar $\left(48-49{ }^{\circ} \mathrm{C}\right)$ as a consequence of the presence of a ratio of PCL arms with a degree of polymerization equal or greater than 30, which initiated the crystallization process. The lowest crystallization temperature was related to the presence of arms with the lowest degree of polymerization and specifically corresponded to the PEI-PCL 10/30 sample. Similar conclusions could be obtained when the evolution of primary nuclei with temperature (Figure 15b) was considered. Namely, the highest temperature at which nuclei were formed was similar. Logically an exponential dependence with decreasing temperatures was found and the number of nuclei became lower than determined for the parent samples with uniform arm lengths. 
Lauritzen-Hoffmann plots (Figure 16) showed a slight difference between slopes from the three studied mixtures, being the corresponding secondary nucleation constants $0.92 \times 10^{5}$, $0.99 \times 10^{5}$ and $1.16 \times 10^{5} \mathrm{~K}^{2}$ for PEI-PCL 10/50, PEI-PCL 30/50 and PEI-PCL 10/30, respectively. Note that only the sample with the lowest average PCL length had a significantly higher value. It should also be pointed out that nucleation constants were clearly higher than determined for the corresponding samples with PCL lengths of 10, 30 and 50, demonstrating a hindered crystallization process for samples with heterogeneous sizes.

Crystallization process was also evaluated from calorimetric experiments as summarized in Table 3. In this case, the Avrami constant seems to increase for all mixtures when the crystallization temperature decreased, a feature that contrast with previous observations on samples having homogeneous arms. In this way, nucleation may follow a different mechanism that implied some sporadic or homogeneous nucleation, which agrees with the thermal nucleation process previously pointed out for mixtures of PEI-PCL stars having different PCL lengths. This process seems more important when crystallization temperature decreased. It is also remarkable that the overall crystallization rates (Table 3) were not proportional to the crystal growth rates for mixtures having PCL arms with the lowest degree of polymerization as shown in Figure 15a for PEI-PCL 10/50. Note, on the contrary the good agreement between temperature evolution of $k$ and $G$ for the PEI-PCL 30/50 mixture.

\section{CONCLUSIONS}


Multiarm star systems constituted by a commercial core of poly(ethyleneimine) and poly( $\varepsilon$ caprolactone) arms with degrees of polymerization of 50,30 and 10 were able to crystallize from both the melt state and diluted $n$-hexanol solutions. In the last case, lamellae with the typical PCL structure were attained, being demonstrated the capability to crystallize even when samples had a degree of polymerization as low as 10 . Morphologies of single crystals were variable, being found the lower degree of perfection when sample had the shortest PCL arms.

Thermal properties showed also a differentiated behaviour for PEI-PCL 10 in terms of low melting and glass transition temperatures and reduced crystallinity. The length of PCL arms had also a remarkable influence on the crystallization kinetics. Specifically, the primary nucleation density and the second nucleation constant increased when the length decreased as consequence of the increase of the nucleation effect caused by a major ratio of PEI cores and the hindered crystal growth due to the existence of short PCL arms.

Crystallization of PEI-PCL $x / y$ mixtures from the melt was basically determined by the larger PCL arms. These were the first to crystallize determining the final thermal properties (e.g. melting and equilibrium melting points) and subsequently the shorter arms were progressively incorporated into the lamellae. A thermal nucleation was characteristic of multiarm star mixtures due to the different crystallization temperature of samples with long and short PCL arms, a feature that contrasts with the athermal nucleation determined for samples with a homogeneous arm length.

\section{Acknowledgments}


Authors are in debt to supports from MINECO and FEDER (MAT2012-36205 and MAT2011-27039-C03-01) and the Generalitat de Catalunya (2014SGR188 and 2014SGR67). A.D. acknowledges a grant from AGAUR. 


\section{REFERENCES}

1. M. Morell, M. Erber, X. Ramis, F. Ferrando, B. Voit, A. Serra, New epoxy thermosets modified with hyperbranched poly(ester-amide) of different molecular weight, Eur. Polym. J. 46 (2010) 1498-1509.

2. J.P. Yang, Z.K. Chen, G. Yang, S.Y. Fu, L. Ye, Simultaneous improvements in the cryogenic tensile strength, ductility and impact strength of epoxy resins by a hyperbranched polymer, Polymer 49 (2008) 3168-3175.

3. M. Morell, X. Ramis, F. Ferrando, Y. Yu, A. Serra, Simultaneous improvements in the cryogenic tensile strength, ductility and impact strength of epoxy resins by a hyperbranched polymer, Polymer 50 (2009) 5374-5383.

4. J. Zhang, Q. Guo, B. Fox, Thermal and mechanical properties of a dendritic hydroxylfunctional hyperbranched polymer and tetrafunctional epoxy resin blends, J. Polym. Sci. Part B: Polym. Phys. 48 (2010) 417-424.

5. E. Zagar, M. Zigon, Aliphatic hyperbranched polyesters based on 2,2is(methylol)propionic acid - Determination of structure, solution and bulk properties, Prog. Polym. Sci. 36 (2011) 53-88.

6. H. Claesson, E. Malmström, M. Johansson, A. Hult. Synthesis and characterization of star branched polyesters with dendritic cores and the effect of structural variations on zeo shear rate viscosity. Polymer 43 (2002) 3511-3518.

7. J.E. Klee, C. Schneider, D. Hölter, A. Burgath, H. Frey, R. Mülhaupt, Hyperbranched polyesters and their application in dental composites: monomers for low shrinking composites, Polym. Adv. Technol. 12 (2001) 346-354. 
8. X. Fernández-Francos, J.M. Salla, A. Mantecón, A. Serra, X. Ramis, Crosslinking of mixtures of DGEBA with 1,6-dioxaspiro[4,4]nonan-2,7-dione initiated by tertiary amines. I. Study of the reaction and kinetic analysis, J. Appl. Polym. Sci. 109 (2008) 2304-2315.

9. D. Foix, M. Erber, B. Voit, A. Lederer, X. Ramis, A. Mantecón, A. Serra, New hyperbranched polyester modified DGEBA thermosets with improved chemical reworkability, Polym. Degrad. Stab. 95 (2010) 445-452.

10. C. Liu, Y. Zhang, J. Huang, Well-Defined star polymers with mixed-arms by sequential polymerization of atom transfer radical polymerization and reverse additionfragmentation chain transfer on a hyperbranched polyglycerol core, Macromolecules 41 (2008) 325-331.

11. H. Gao, K. Matyjaszewski, Synthesis of star polymers by a new "core-first" method: sequential polymerization of cross-linker and monomer, Macromolecules 41 (2008) 11181125.

12. B. Mendrek, B. Trzebicka, W. Walach, A. Dworak, Solution behavior of 4-arm poly(tert-butyl acrylate) star polymers, Eur. Polym. J. 46 (2010) 2341-2351.

13. M. Morell, A. Lederer, X. Ramis, B. Voit, A. Serra, Multiarm star poly(glycidol)block-poly(e-caprolactone) of different arm lengths and their use as modifiers of diglycidylether of bisphenol a thermosets, J. Polym. Sci. Part A: Polym. Chem. 49 (2011) 2395-2406.

14. M. Morell, X. Ramis, F. Ferrando, A. Serra, Effect of polymer topology on the curing process and mechanical characteristics of epoxy thermosets modified with linear or multiarm star poly( $\varepsilon$-caprolactone), Polymer 52 (2011) 4694-4702. 
15. J.M. Morancho, A. Cadenato, X. Ramis, M. Morell, X. Fernández-Francos, J. M. Salla, A. Serra, Thermal curing and photocuring of a DGEBA modified with multiarm star poly(glycidol)- $b$-poly( $\varepsilon$-caprolactone) polymers of different arm lengths. J Therm Anal Calorim (2013) 114:409-416.

16. W. Fan, L. Wang, S. Zheng, Nanostructures in Thermosetting Blends of Epoxy Resin with Polydimethylsiloxane-block-poly(e-caprolactone)-block-polystyrene ABC Triblock Copolymer, Macromolecules 42 (2009) 327-336.

17. N. Hameed, Q. Guo, T. Hanley, Y.W. Mai, Hydrogen bonding interactions, crystallization, and surface hydrophobicity in nanostructured epoxy/block copolymer blends, J. Polym. Sci. Part B: Polym. Phys. 48 (2010) 790-800.

18. L.H. Sperling, Introduction to Physical Polymer Science, Wiley Interscience, Hoboken, 2006. p. 573.

19. E. Núñez, C. Ferrando, E. Malmström, H. Claesson, P.E. Werner, U.W. Gedde, Crystal structure, melting behaviour and equilibrium melting point of star polyesters with crystallisable poly( $\varepsilon$-caprolactone) arms, Polymer 45 (2004) 5251-2563.

20. J. Coi, S.Y. Kwak, Architectural effects of poly( $\varepsilon$-caprolactone)s on the crystallization kinetics. Macromolecules 37 (2004) 3745-3754.

21. E. Núñez, C. Ferrando, E. Malmström, H. Claesson, U. W. Gedde. Crystallization Behavior and Morphology of Star Polyesters with Poly( $\varepsilon$-Caprolactone) Arms. J. Macromol. Sci. Part B Phys. 43 (2004) 1143.1160.

22. B.G. Risch, G.L. Wilkes, J.M. Warakomski, Crystallization kinetics and morphological features of star-branched nylon-6: Effect of branch-point functionality, Polymer 34 (1993) 2330-2343. 
23. E. Núñez, U.W. Gedde, Single crystal morphology of star-branched polyesters with crystallisable poly(e-caprolactone) arms, Polymer 46 (2005) 5992-6000.

24. S.J. Organ, A. Keller, Solution crystallization of polyethylene at high temperatures. Part 1. Lateral crystal habits, J. Mater. Sci. 20 (1985) 1571-1585.

25. W. Xie, N. Jiang, Z. Gan, Effects of multi-arm structure on crystallization and biodegradation of star-shaped poly(E-caprolactone), Macromol. Biosci. 8 (2008) 775-784.

26. C. Acebo, X. Fernández-Francos, F. Ferrando, A. Serra , J.M. Salla, Xavier Ramis, Multiarm star with poly(ethyleneimine) core and poly( $\varepsilon$-caprolactone) arms as modifiers of diglycidylether of bisphenol A thermosets cured by 1-methylimidazole, React. Funct. Polym. 73 (2013) 431-441.

27. V. Crescenzi, G. Manzini, G. Calzolari, C. Borri, Thermodynamics of fusion of poly- $\beta$ propiolactone and poly- $\varepsilon$-caprolactone. Comparative analysis of the melting of aliphatic polylactone and polyester chains, Eur. Polym. J. 8 (1972) 449-463.

28. S. Nakagawa, K. Kadena, T. Ishizone, S. Nojima, T. Shimizu, K. Yamaguchi, S. Nakahama, Crystallization behavior and crystal orientation of poly( $\varepsilon$-caprolactone) homopolymers confined in nanocylinders: Effects of nanocylinder dimension, Macromolecules 45 (2012) 1892-1900.

29. A. Muñoz-Bonilla, M.L. Cerrada, M. Fernández-García, A. Kubacka, M. Ferrer, M. Fernández-García, Biodegradable polycaprolactone-titania nanocomposites: preparation, characterization and antimicrobial properties, Int. J. Mol. Sci. 14 (2013) 9246-9266. 
30. J.D. Hoffman, J.J. Weeks, Melting process and the equilibrium melting temperature of polychlorotrifluoroethylene, J. Res. Natl. Bur. Stand. 66 (1962) 13-28.

31. G. Strobl, From the melt via mesomorphic and granular crystalline layers to lamellar crystallites: a major route followed in polymer crystallization? Eur. Phys. J. E3 (2000) 165183.

32. H. Marand, J. Xu, S. Srinivas, Determination of the equilibrium melting temperature of polymer crystals: Linear and nonlinear Hoffman-Weeks extrapolations, Macromolecules 31 (1998) 8219.

33. J.D. Hoffman, G.T. Davies, J.I. Lauritzen Jr., Treatise in solid state chemistry, N.B. Hannay (Ed.), Plenum Press, New York, 1976, Chapter 7, pp. 497-614.

34. J.P. Huang, X. Xu, X.L. Luo, CD.Z. Ma, Molecular weight dependence of the melting behavior of poly(E-caprolactone), Chinese. J. Polym. Sci. 20 (2002) 45-51.

35. Y. Furuhashi, P. Sikorski, E. Atkins, T. Iwata, Y. Doi, Structure and morphology of the aliphatic polyester poly( $\delta$-valerolactone) in solution-grown, chain-folded Lamellar crystals, J. Polym. Sci. Polym. Phys. 39 (2001) 2622-2634.

36. E. Pouget, A. Almontassir, M.T. Casas, J. Puiggalí, On the crystalline structures of poly(tetramethylene adipate), Macromolecules 36 (2003) 698-705.

37. Y. Chatani, Y. Okita, H. Tadokoro, Y. Yamashita, Structural studies of polyesters. III. Crystal structure of poly- $\varepsilon$-caprolactone, Polymer 1 (1970) 555-562.

38. H. Hu, D.L. Dorset, Crystal structure of poly( $\varepsilon$-capro1actone), Macromolecules 23 (1990) 4604-4607. 
39. T. Iwata, Y. Doi, Morphology and enzymatic degradation of poly( $\varepsilon$-caprolactone) single crystals: does a polymer single crystal consist of micro-crystals?, Polym. Int. 51 (2002) 852-858.

40. S. Gestí, A. Almontassir, M.T. Casas, J. Puiggalí, Crystalline structure of poly(hexamethylene adipate). Study on the morphology and the enzymatic degration of single Crystal, Biomacromolecules 7 (2006) 799-808.

41. S. Gestí, M. T. Casas, J. Puiggalí, Crystalline structure of poly(hexamethylene succinate) and single crystal degradation studies, Polymer 48 (2007) 5088-5097.

42. S. Gestí, A: Almontassir, M. T. Casas, J. Puiggalí, Molecular packing and crystalline morphologies of biodegradable poly(alkylene dicarboxylate)s derived from 1,6-hexanediol, Polymer 45 (2004) 8845-8861.

43. M. Avrami, Kinetics of phase change. I General Theory, J. Chem. Phys. 7 (1939) 11031112.

44. M. Avrami, Kinetics if phase change. II Transformation time relations for random distribution of nuclei, J. Chem. Phys. 8 (1940) 212-224.

45. T.W. Chan, A.I. Isayev, Quiescent polymer crystallization: Modeling and measurements, Polym. Eng. Sci. 34 (1994) 461-471.

46. J. G. Fatou, C. Marco, L. Maldelkern, The crystallization kinetics of low-molecularweight polyethylene fractions, Polymer 31 (1990) 890-898.

47. H. Lu, J. Qiao, Y. Yang, Effect of isotacticity distribution on crystallization kinetics of polypropylene, Polym. Int. 51 (2002) 1304.

48. J.M. Kenny, A. Maffezzoli, R. Nicolais, A new kinetic model for polymer crystallization derived by calorimetric analysis, Thermochim. Acta. 227 (1993) 83-95. 
49. J.I. Lauritzen, J.D. Hoffman, Extension of theory of growth of chain folded polymer crystals to large undercoolings, J. Appl. Phys. 44 (1973) 4340-4352.

50. D. Turnbull, J.C. Fisher, Rate of nucleation in condensed systems, J. Chem. Phys. 17 (1949) 71-73.

51. T. Suzuki, A.J. Kovacs, Temperature dependence of spherulitic growth rate of isotactic polystyrene. A critical comparison with the kinetic theory of surface nucleation, Polym. J. 1 (1970) 82-100. 


\section{FIGURE CAPTIONS}

Figure 1. a) Chemical structure of multiarm star PEI-PCL $x$ copolymers. b) Model of lamellar crystals grown from multiarm star PEI-PCL copolymers.

Figure 2. ${ }^{1} \mathrm{H}-\mathrm{NMR}$ spectrum in $\mathrm{CDCl}_{3}$ of PEI-PCL10 multiarm star.

Figure 3. DSC traces obtained with PEI-PCL 10 (a) and PEI-PCL 50 (b) samples, corresponding from down to up to the heating run $\left(20^{\circ} \mathrm{C} / \mathrm{min}\right)$ of the as-synthesized sample, the cooling run $\left(10^{\circ} \mathrm{C} / \mathrm{min}\right)$ after keeping the sample in the melt state for three minutes, the subsequent heating run $\left(20^{\circ} \mathrm{C} / \mathrm{min}\right)$ of the non-isothermally crystallized sample (c) and the heating run $\left(20^{\circ} \mathrm{C} / \mathrm{min}\right)$ of a sample previously cooled from the melt

state at the maximum rate allowed by the equipment. Insets show the glass transition temperatures detected in the third heating run of the multiarm star samples and the first heating run of a representative PCL sample with a molecular weight of 11,400 g/mol.

Figure 4. DSC heating scans $\left(20^{\circ} \mathrm{C} / \mathrm{min}\right)$ of PEI-PCL 10 (a), PEI-PCL 30 (b) and PEI-PCL 50 (c) samples isothermally crystallized at the indicated temperatures.

Figure 5. Hoffman-Weeks plot of temperatures corresponding to endothermic melting peaks versus crystallization temperature for PEI-PCL 10, PEI-PCL 30 and PEI-PCL 50. Equilibrium melting temperatures are explicitly indicated at the intersection point with the $T_{m}=T_{c}$ line.

Figure 6. Transmission electron micrographs of PCL (a), PEI-PCL 10 (b), PEI-PCL 30 (c) and PEI-PCL 50 (d) samples isothermally crystallized from $n$-hexanol at 40, 40, 40 and 60 ${ }^{\circ} \mathrm{C}$, respectively. The arrows indicate the $b$ crystallographic axis direction for the different 
crystals. The inset of (b) shows more clearly the lanceolate/lenticular morphology of PEPCL 10 single crystals.

Figure 7. Electron diffraction pattern taken from PEI-PCL 10 (a), PEI-PCL 30 (b) and PEIPCL 50 (c) lamellar crystals obtained as above indicated.

Figure 8. Polarized optical micrographs of PEI-PCL 10 (a), PEI-PCL 30 (b) and PEI-PCL 50 (c) isothermally crystallized at $40^{\circ} \mathrm{C}, 48^{\circ} \mathrm{C}$ and $49^{\circ} \mathrm{C}$, respectively.

Figure 9. a) Exothermic DSC peaks corresponding to isothermal crystallizations of PEIPCL 10 at temperatures between 28 and $37{ }^{\circ} \mathrm{C}$. b) Development of the relative degree of crystallinity of PEI-PCL 10 at different crystallization temperatures. c) Avrami plots corresponding to isothermal crystallization of PEI-PCL 10 at the above indicated temperatures.

Figure 10. a) Plots of the radius of PEI-PCL 10 spherulites versus crystallization time for isothermal melt crystallizations performed between 28 and $40{ }^{\circ} \mathrm{C}$. b) Experimental spherulitic growth rates (solid lines and full symbols) and overall crystallization rates (dashed lines and open symbols) of PEI-PCL 10, PEI-PCL 30 and PEI-PCL 50 samples.

Figure 11. a) Change in the nucleation density with isothermal crystallization temperature for PEI-PCL 10, PEI-PCL 30 and PEI-PCL 50 samples. b) Plot of $\ln G+U^{*} / R\left(T_{c^{-}} T_{\infty}\right)$ versus $1 / T_{c}(\Delta T) f$ to determine the $K_{g}$ secondary nucleation constant of PEI-PCL 10, PEIPCL 30 and PEI-PCL 50 samples. 
Figure 12. DSC traces obtained with PEI-PCL 10/50 samples following the same protocol indicated in Figure 2.

Figure 13. Hoffman-Weeks plot of temperatures corresponding to endothermic melting peaks versus crystallization temperature for PEI-PCL 10/30, PEI-PCL 10/50 and PEI-PCL 30/50 samples. Equilibrium melting temperatures are explicitly indicated at the intersection point with the $T_{m}=T_{c}$ line.

Figure 14. Polarized optical micrographs of PEI-PCLX 10/50 isothermally crystallized at $35^{\circ} \mathrm{C}$.

Figure 15. a) Experimental spherulitic growth rates (solid lines, full symbols) of PEI-PCL 10/30, PEI-PCL 10/50 and PEI-PCL 30/50. For the sake of completeness experimental overall crystallization rates (dashed lines and open symbols) are also plot for PEI-PCL 10/50 and PEI-PCL 30/50 samples. b) Change in the nucleation density with isothermal crystallization temperature for PEI-PCL 10/30, PEI-PCL 10/50 and PEI-PCL 30/50 samples.

Figure 16. Plot of $\ln G+U^{*} / R\left(T_{c}-T_{\infty}\right)$ versus $1 / T_{c}(\Delta T) f$ to determine the $K_{g}$ secondary nucleation parameter of PEI-PCL 10/30, PEI-PCL 10/50 and PEI-PCL 30/50 samples. 
Table 1. Main thermal properties determined by DSC for PEI-PCL $x$ samples.

\begin{tabular}{|c|c|c|c|c|c|c|c|c|c|}
\hline \multirow[b]{2}{*}{ Sample } & \multicolumn{2}{|c|}{$1^{\text {st }}$ Heating scan } & \multicolumn{2}{|c|}{ Cooling scan } & \multicolumn{2}{|c|}{$2^{\text {nd }}$ Heating scan } & \multicolumn{3}{|c|}{$3^{\text {rd }}$ Heating scan } \\
\hline & $\begin{array}{c}T_{f} \\
\left({ }^{\circ} \mathbf{C}\right)\end{array}$ & $\begin{array}{r}\Delta \boldsymbol{H}_{\mathbf{f}} \\
(\mathrm{J} / \mathbf{g})\end{array}$ & $\begin{array}{c}T_{c} \\
\left({ }^{\circ} \mathbf{C}\right)\end{array}$ & $\begin{array}{c}\Delta \boldsymbol{H}_{\boldsymbol{c}} \\
(\mathbf{J} / \mathbf{g})\end{array}$ & $\begin{array}{c}T_{f} \\
\left({ }^{\circ} \mathbf{C}\right)\end{array}$ & $\begin{array}{c}\Delta \boldsymbol{H}_{\mathbf{f}} \\
(\mathbf{J} / \mathbf{g})\end{array}$ & $\begin{array}{c}T_{g} \\
\left({ }^{\circ} \mathbf{C}\right)\end{array}$ & $\begin{array}{c}T_{f} \\
\left({ }^{\circ} \mathbf{C}\right)\end{array}$ & $\begin{array}{r}\Delta \boldsymbol{H}_{\mathbf{f}} \\
(\mathrm{J} / \mathrm{g})\end{array}$ \\
\hline PEI-PCL 10 & $\mathbf{4 4 . 8}, 48.3$ & 74.5 & 19.5 & 76.9 & 44.7, 48.2 & 76.6 & -62.0 & 43.1, 48.6 & 75.2 \\
\hline PEI-PCL 30 & $\mathbf{6 2 . 7}, 63.9$ & 115.7 & 32.2 & 87.8 & 53.7 & 89.7 & -57.0 & 53.2 & 88.3 \\
\hline PEI-PCL 50 & 62.4 & 117.1 & 32.7 & 89.7 & 54.6 & 90.5 & -57.0 & $\mathbf{5 4 . 1}, 55.5$ & 90.5 \\
\hline
\end{tabular}

${ }^{a}$ When multiple melting peaks are observed the most intense one is indicated in bold numbers. 
Table 2. Main crystallization kinetic parameters determined by DSC for PEI-PCL $x$ samples.

\begin{tabular}{|c|c|c|c|c|c|c|}
\hline Sample & $\begin{array}{c}T \\
\left({ }^{\circ} \mathrm{C}\right)\end{array}$ & $\begin{array}{c}Z .10^{6} \\
\left(\mathrm{~s}^{-\mathrm{n}}\right)\end{array}$ & $n$ & $\begin{array}{c}k .10^{3} \\
\left(\mathrm{~s}^{-1}\right)\end{array}$ & $\begin{array}{c}1 / \tau_{1 / 2} .10^{3} \\
\left(\mathrm{~s}^{-1}\right)\end{array}$ & $\begin{array}{c}(\mathrm{Z} / \ln 2)^{1 / n} \\
\left(\mathrm{~s}^{-1}\right)\end{array}$ \\
\hline \multicolumn{7}{|c|}{ PEI-PCL 10} \\
\hline & 28 & 39.40 & 2.19 & 9.69 & 11.43 & 11.46 \\
\hline & 30 & 10.57 & 2.34 & 7.46 & 8.70 & 8.72 \\
\hline & 32 & 1.534 & 2.47 & 4.40 & 5.09 & 5.10 \\
\hline & 35 & 0.3179 & 2.40 & 1.94 & 2.27 & 2.29 \\
\hline & 37 & 0.0527 & 2.47 & 1.13 & 1.31 & 1.31 \\
\hline \multicolumn{7}{|c|}{ PEI-PCL 30} \\
\hline & 40 & 517.13 & 1.60 & 8.87 & 11.55 & 11.16 \\
\hline & 43 & 1.4564 & 2.22 & 2.33 & 2.77 & 2.75 \\
\hline & 45 & 0.2078 & 2.35 & 1.44 & 1.68 & 1.68 \\
\hline & 47 & 0.0059 & 2.46 & 0.45 & 0.52 & 0.52 \\
\hline & 48 & 0.0012 & 2.48 & 0.26 & 0.29 & 0.30 \\
\hline \multicolumn{7}{|c|}{ PEI-PCL 50} \\
\hline & 40 & 34.522 & 2.37 & 13.14 & 15.34 & 15.29 \\
\hline & 43 & 11.738 & 2.16 & 5.18 & 6.21 & 6.18 \\
\hline & 45 & 24.333 & 1.81 & 2.90 & 3.57 & 3.57 \\
\hline & 47 & 1.4454 & 2.10 & 1.63 & 1.91 & 1.94 \\
\hline & 48 & 0.0800 & 2.31 & 0.85 & 0.99 & 0.99 \\
\hline & 49 & 0.0012 & 2.64 & 0.42 & 0.53 & 0.48 \\
\hline
\end{tabular}


Table 3. Main crystallization kinetic parameters determined by DSC for PEI/PCL $x / y$ samples.

\begin{tabular}{|c|c|c|c|c|c|c|}
\hline Sample & $\begin{array}{c}T \\
\left({ }^{\circ} \mathrm{C}\right)\end{array}$ & $\begin{array}{l}Z .10^{6} \\
\left(\mathrm{~s}^{-\mathrm{n}}\right)\end{array}$ & $n$ & $\begin{array}{l}k .10^{3} \\
\left(\mathrm{~s}^{-1}\right)\end{array}$ & $\begin{array}{c}1 / \tau_{1 / 2} .10^{3} \\
\left(\mathrm{~s}^{-1}\right)\end{array}$ & $\begin{array}{c}(\mathrm{Z} / \mathrm{ln} 2)^{1 / \mathrm{n}} \cdot \mathbf{1 0}^{3} \\
\left(\mathrm{~s}^{-1}\right)\end{array}$ \\
\hline \multicolumn{7}{|c|}{ PEI-PCL 10/30 } \\
\hline & 33 & 2.4774 & 2.94 & 12.54 & 14.16 & 14.03 \\
\hline & 35 & 0.5113 & 3.03 & 8.38 & 9.43 & 9.46 \\
\hline & 38 & 6.8328 & 2.44 & 7.58 & 8.62 & 8.87 \\
\hline & 40 & 6.0534 & 2.19 & 4.21 & 5.04 & 4.90 \\
\hline & 43 & 1.2879 & 2.10 & 1.59 & 1.88 & 1.87 \\
\hline & 45 & 0.1025 & 2.30 & 0.92 & 1.07 & 1.07 \\
\hline \multicolumn{7}{|c|}{ PEI-PCL 10/50 } \\
\hline & 33 & 7.4148 & 2.69 & 12.50 & 14.28 & 14.19 \\
\hline & 35 & 6.9214 & 2.44 & 7.80 & 9.09 & 8.92 \\
\hline & 38 & 0.5138 & 2.61 & 3.87 & 4.46 & 4.48 \\
\hline & 40 & 0.0963 & 2.65 & 2.27 & 2.69 & 2.58 \\
\hline & 43 & 3.6542 & 1.94 & 1.57 & 1.89 & 1.90 \\
\hline & 45 & 0.0691 & 2.26 & 0.67 & 0.79 & 0.79 \\
\hline \multicolumn{7}{|c|}{ PEI-PCL 30/50 } \\
\hline & 38 & 1.3664 & 3.16 & 14.05 & 15.58 & 15.65 \\
\hline & 40 & 0.0696 & 3.31 & 6.89 & 7.70 & 7.69 \\
\hline & 42 & 0.0095 & 3.18 & 3.01 & 3.39 & 3.37 \\
\hline & 43 & 0.0175 & 2.87 & 2.00 & 2.26 & 2.25 \\
\hline & 45 & 0.4102 & 2.22 & 1.32 & 1.09 & 1.52 \\
\hline & 47 & 0.2445 & 2.03 & 0.56 & 0.65 & 0.66 \\
\hline
\end{tabular}


a)

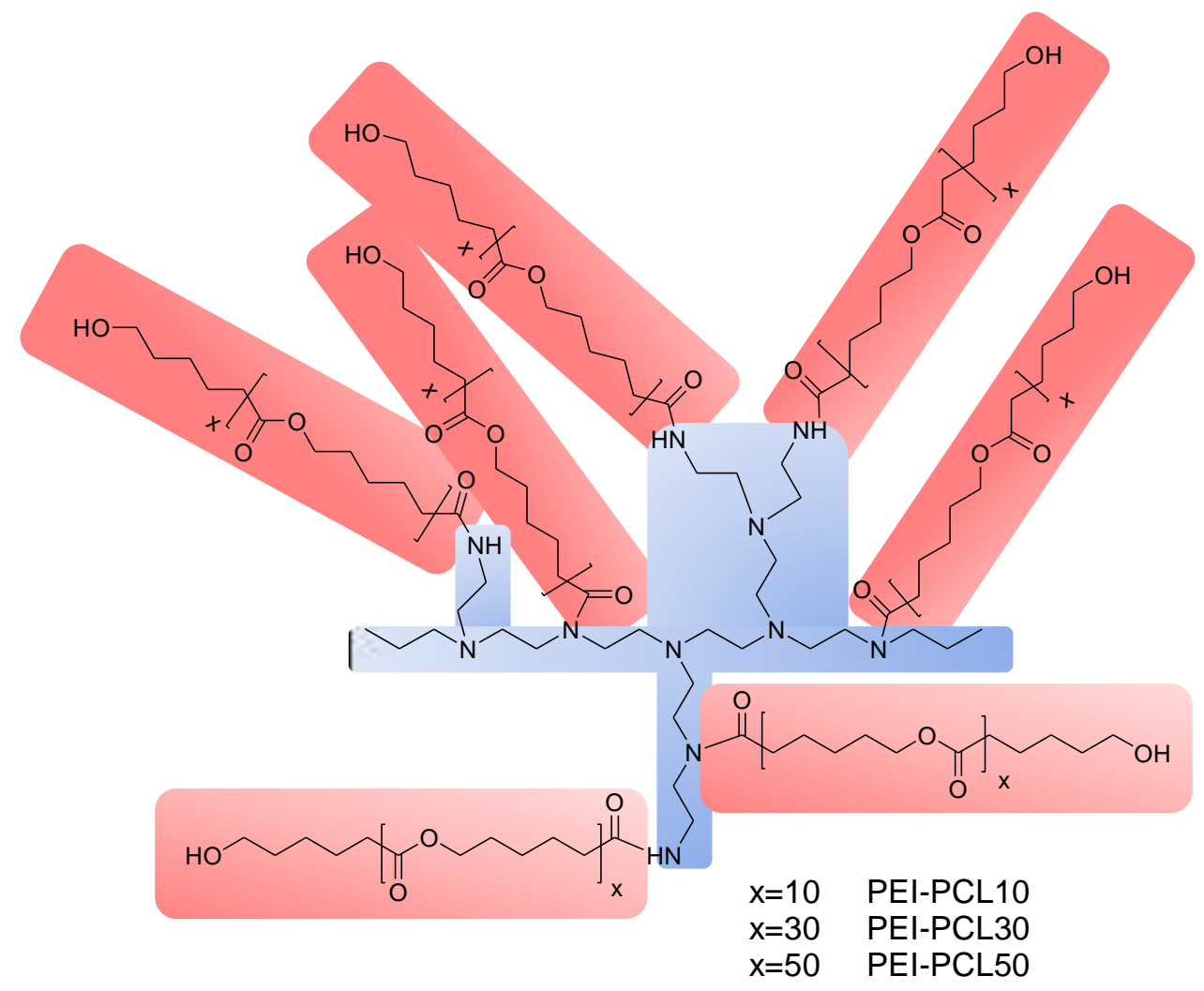

b)

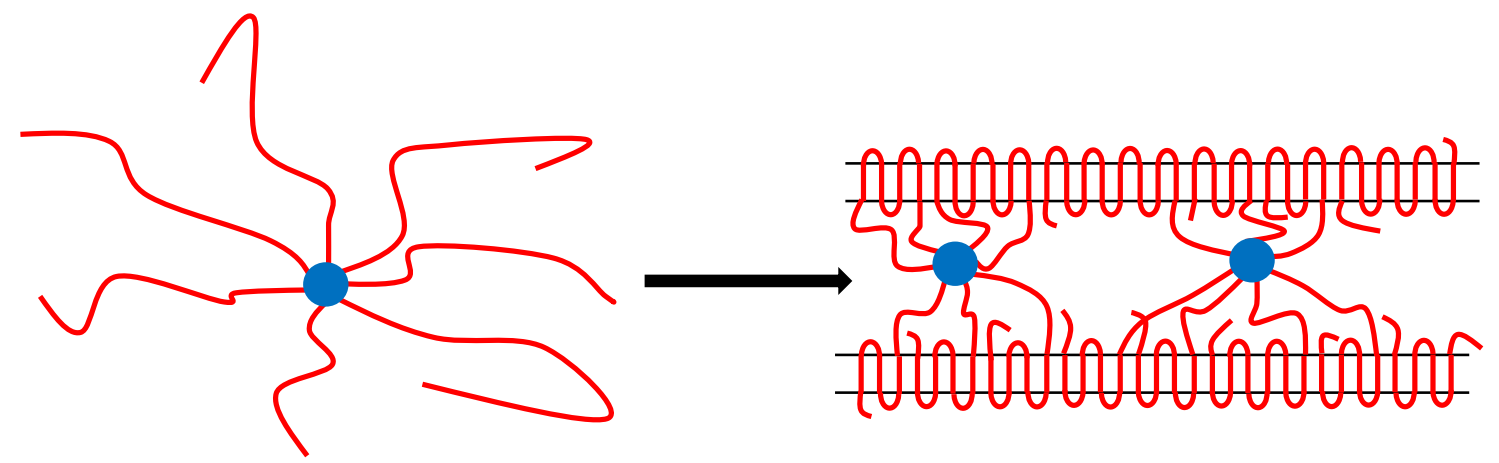

PEI-PCL multiarm star

Lamellar structure developed from PEI cores 


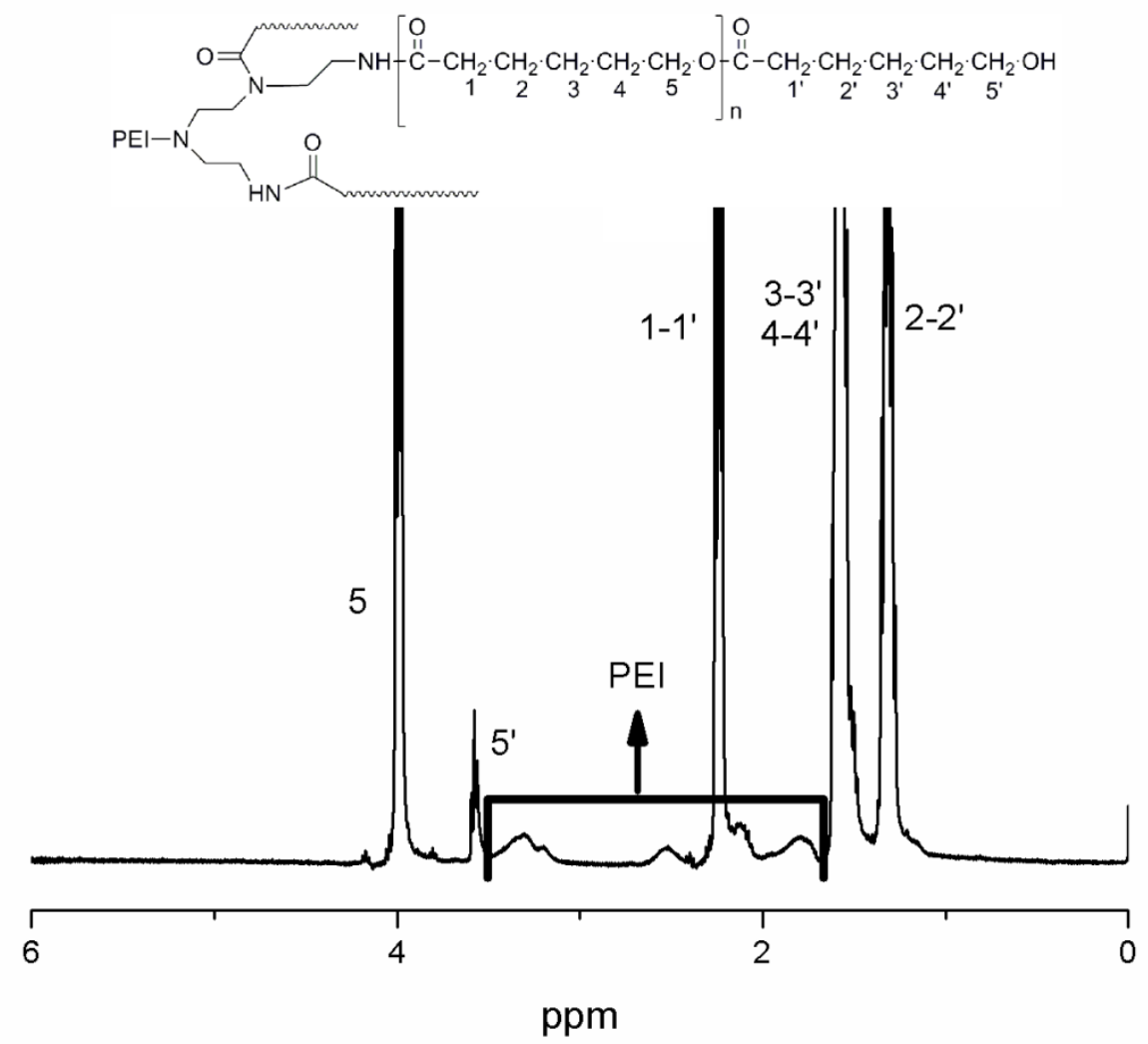

FIGURE 2

Díaz et al. 


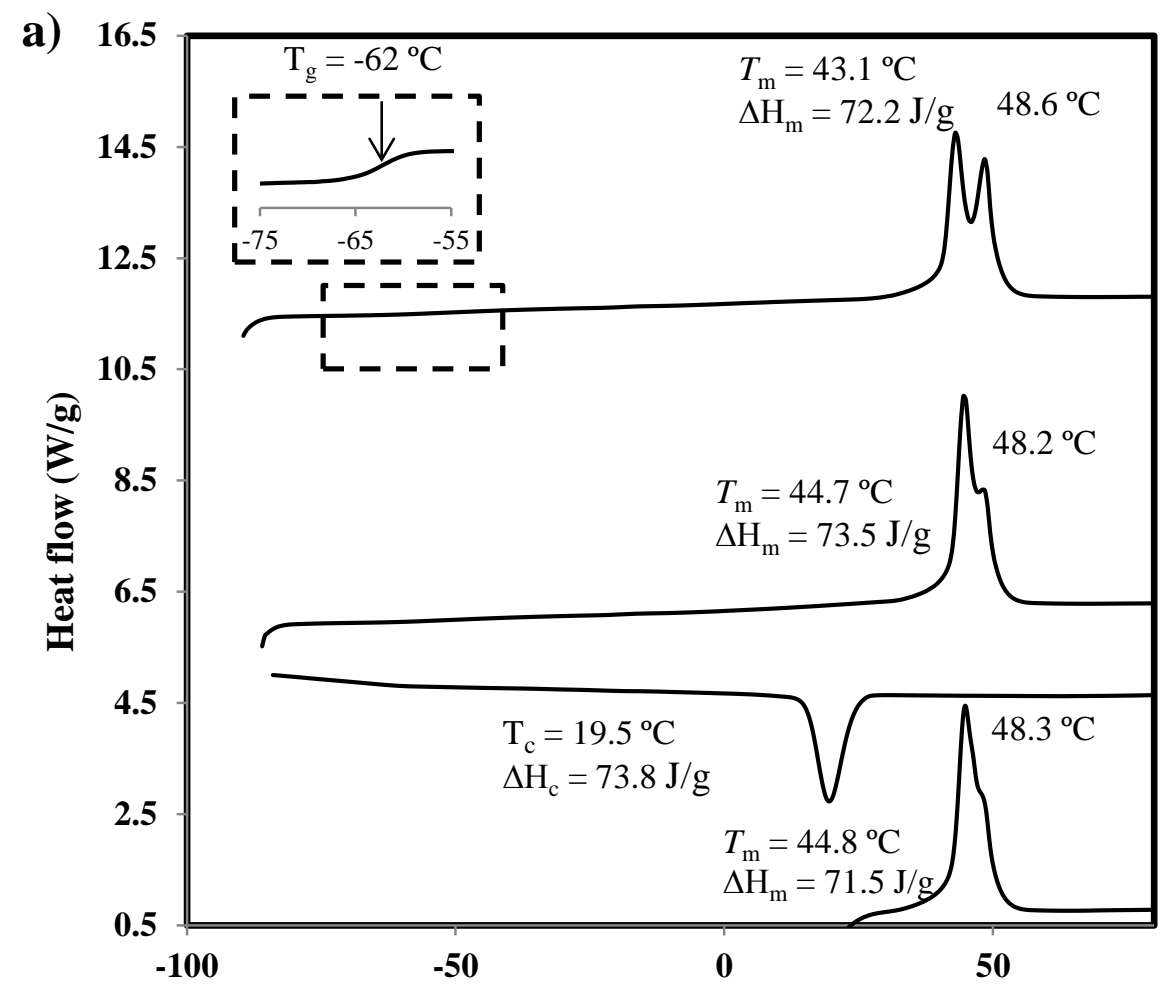

Temperature $\left({ }^{\circ} \mathrm{C}\right)$

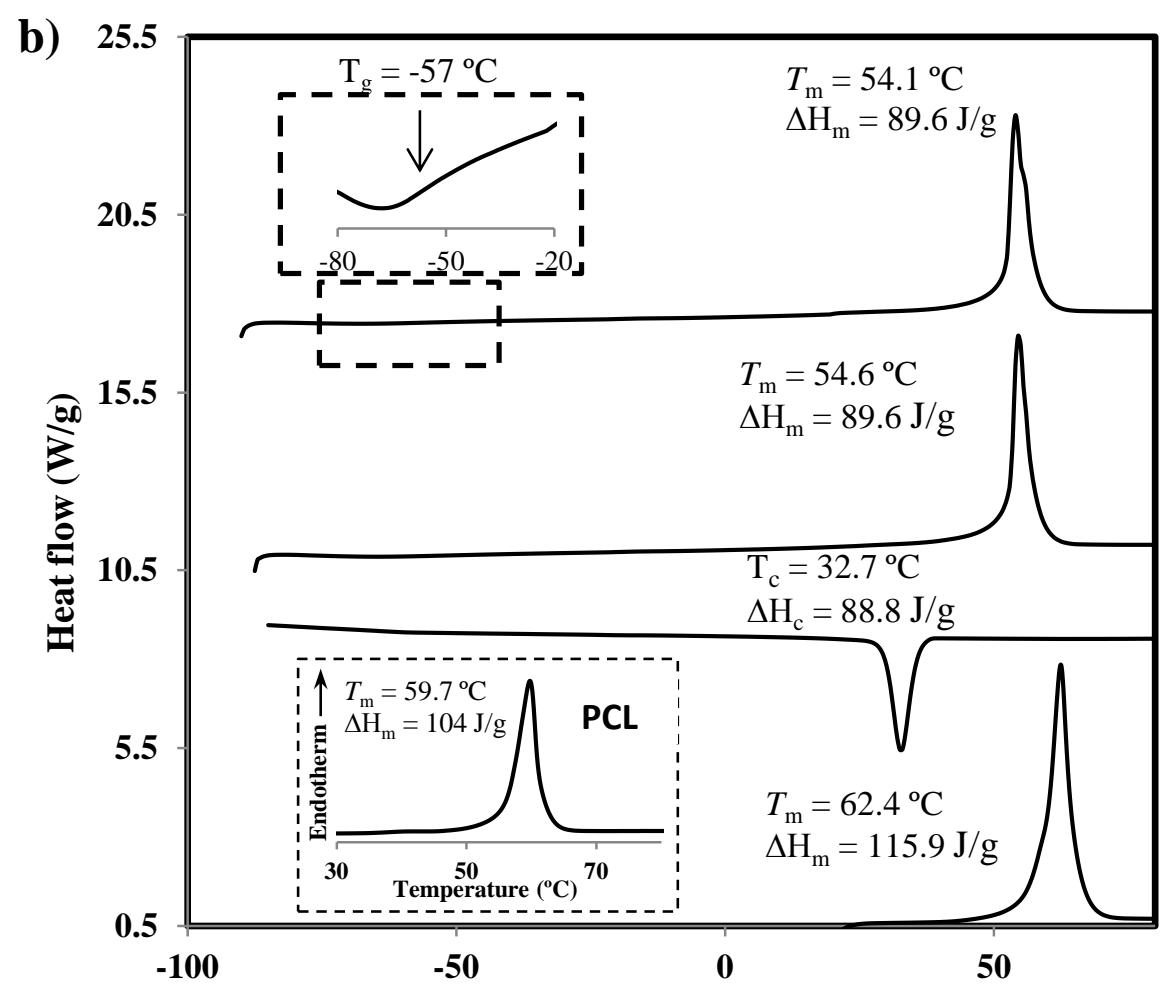

Temperature $\left({ }^{\circ} \mathrm{C}\right)$

FIGURE 3

Díaz et al. 


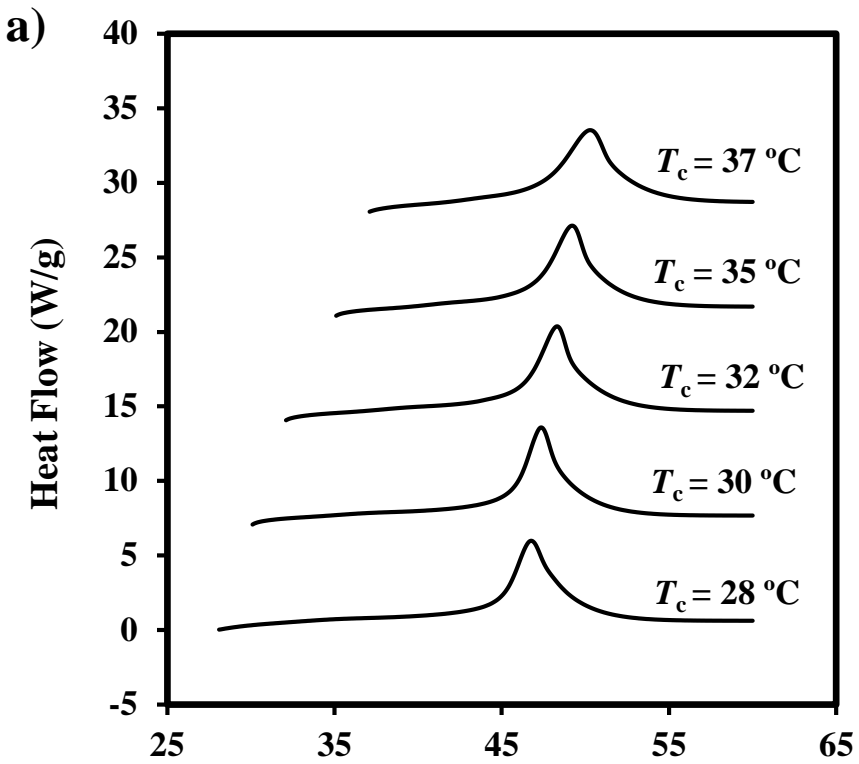

Temperature $\left({ }^{\circ} \mathrm{C}\right)$
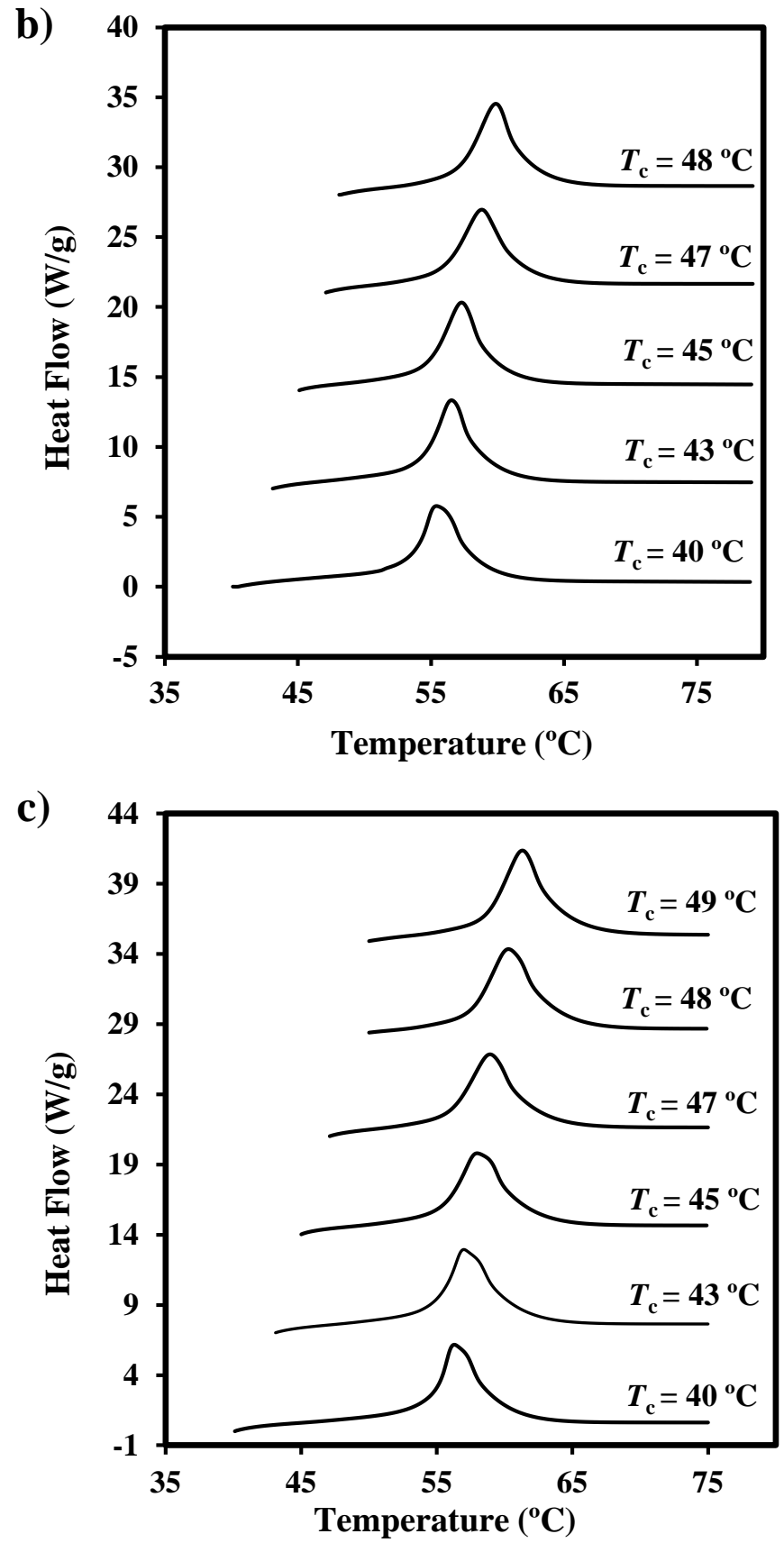


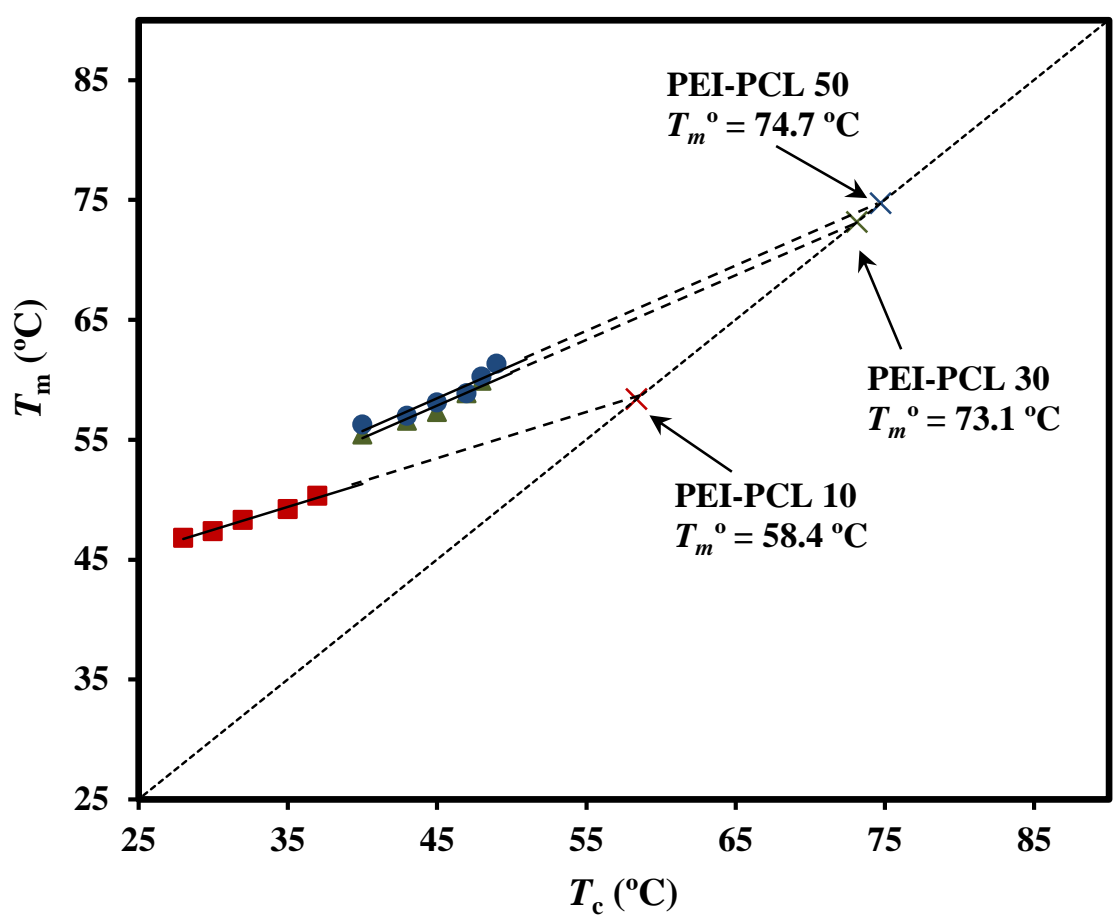



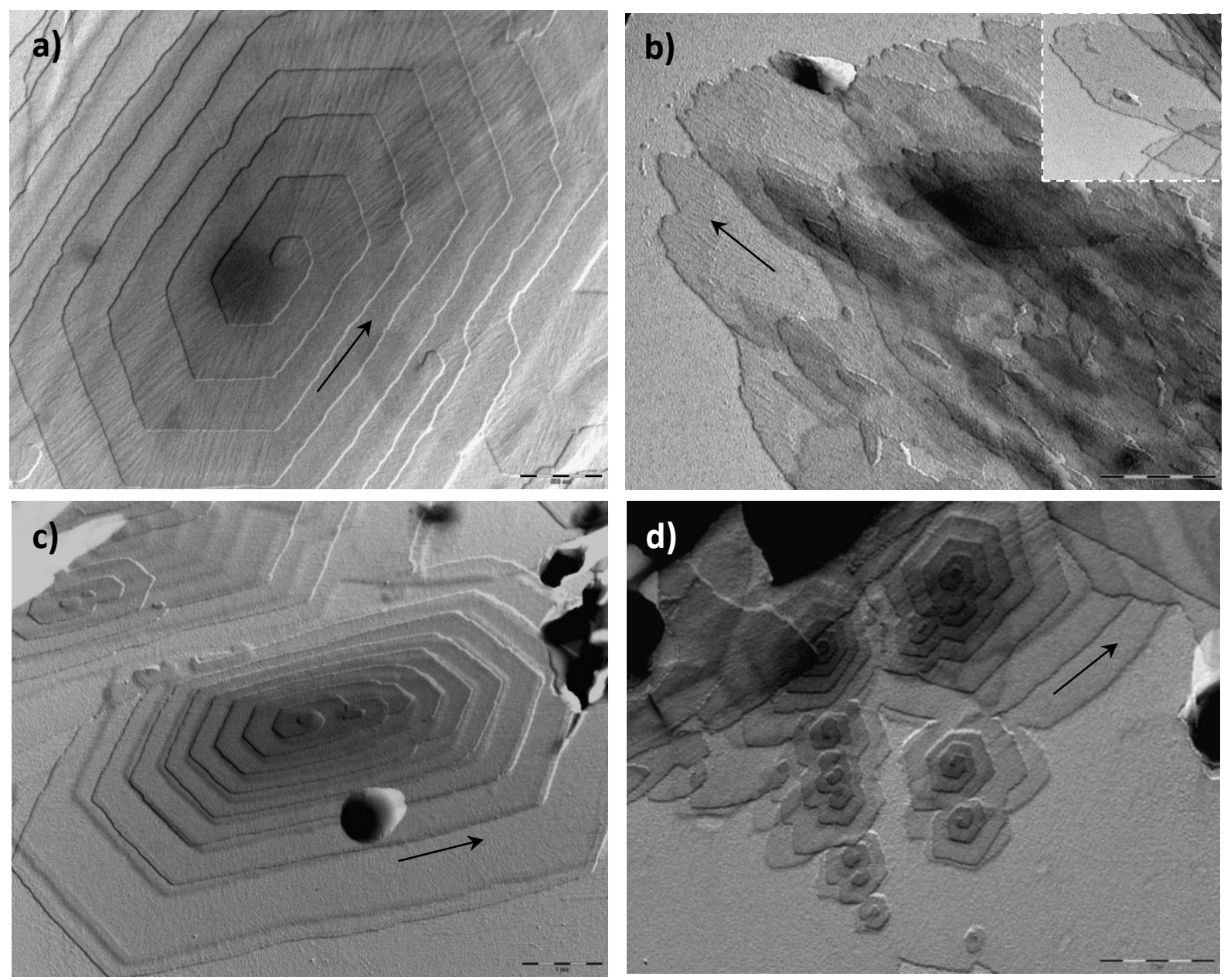


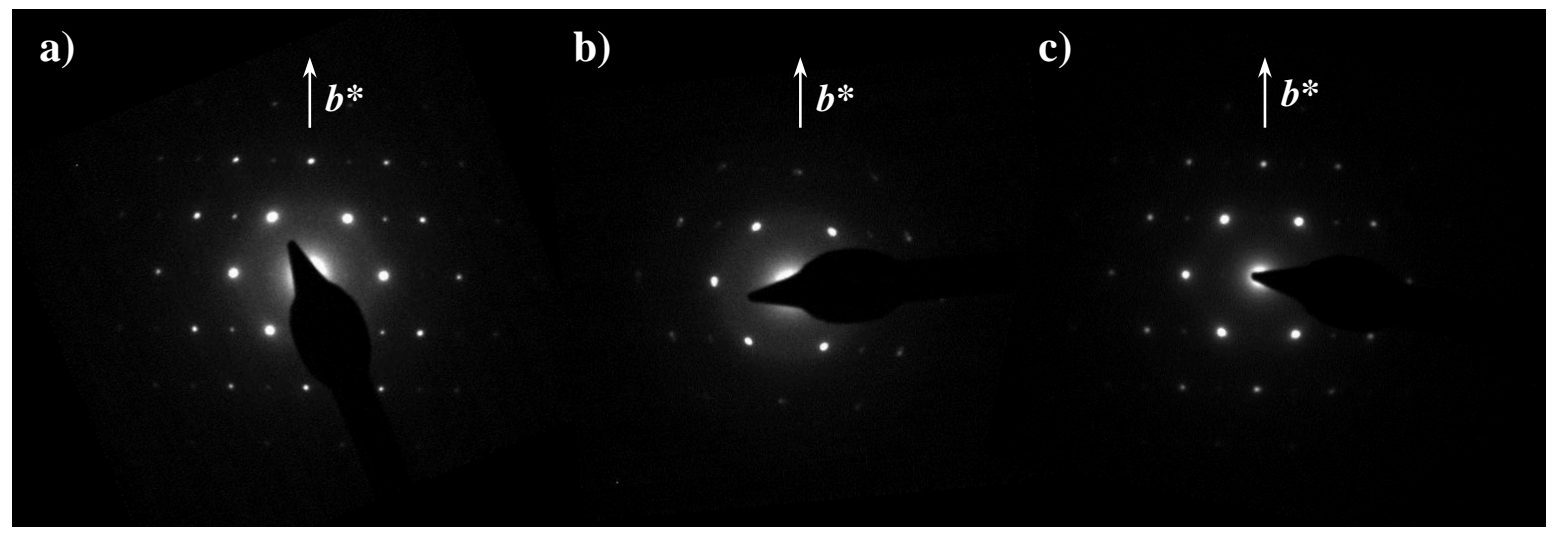

FIGURE 7

Díaz et al. 

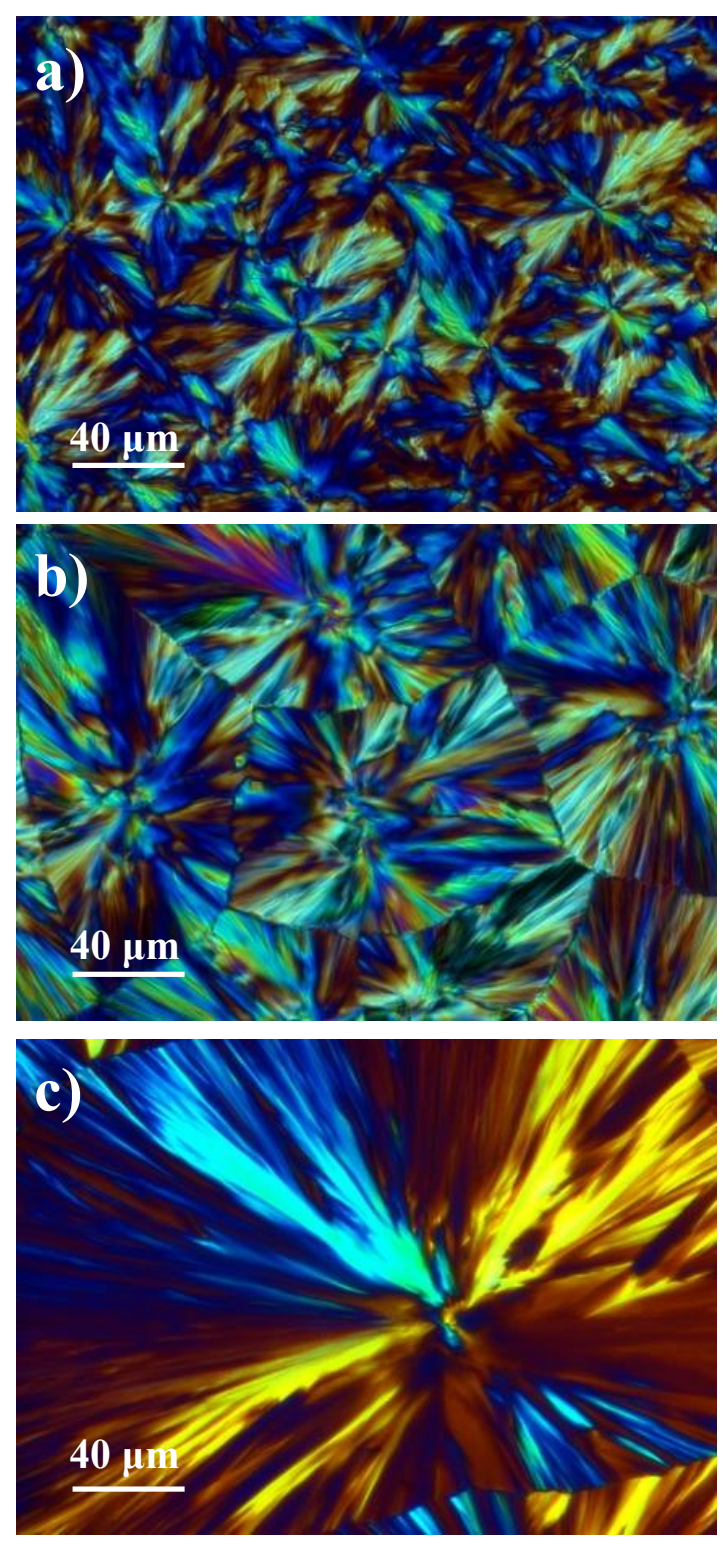

FIGURE 8

Díaz et al. 
a)

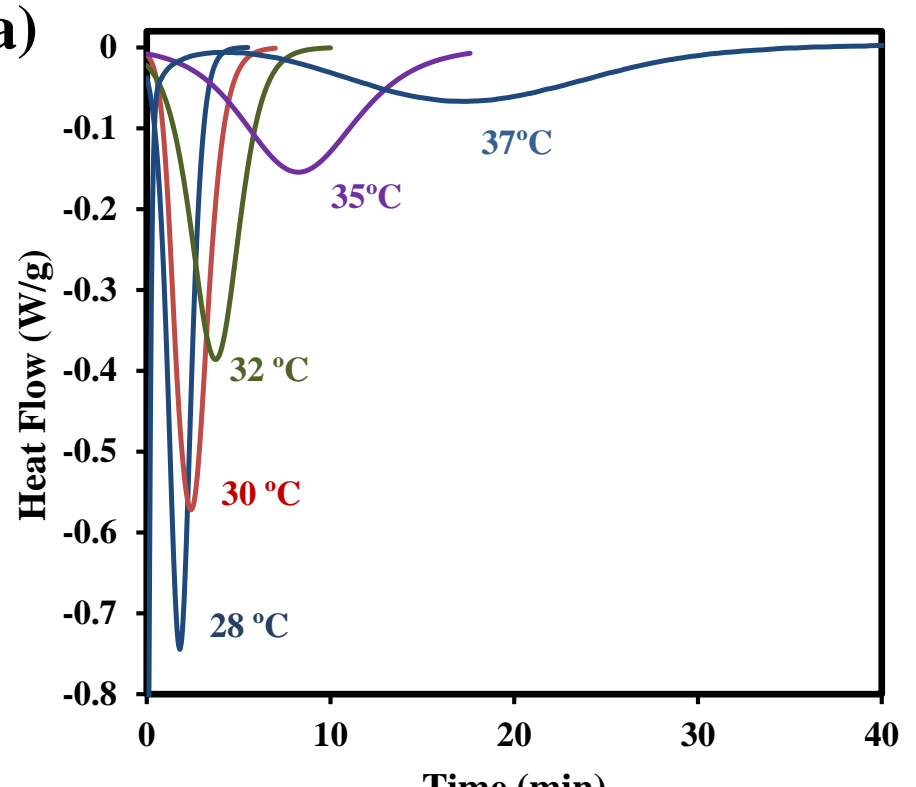

b)

Time (min)
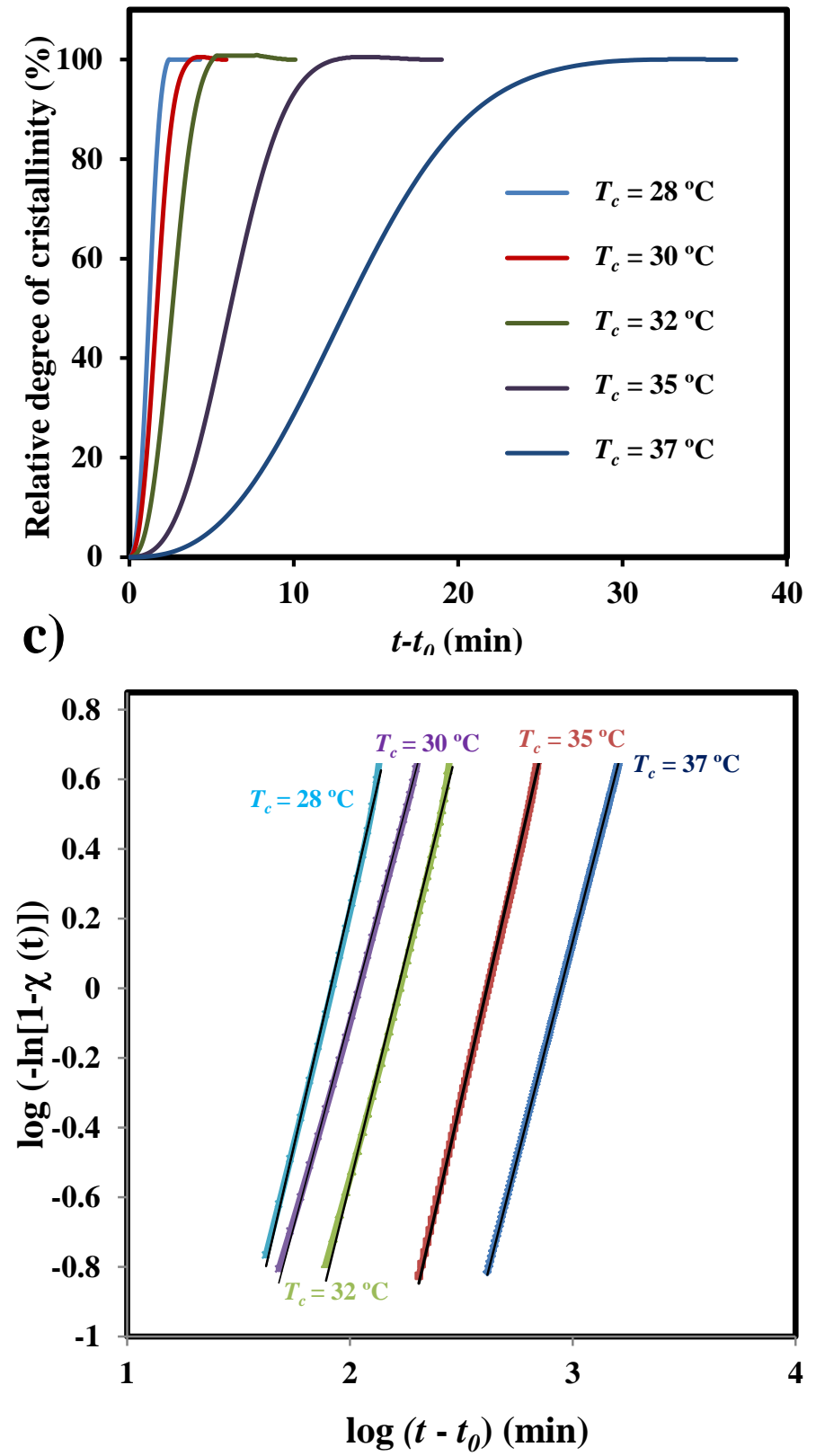

FIGURE 9

Díaz et al. 

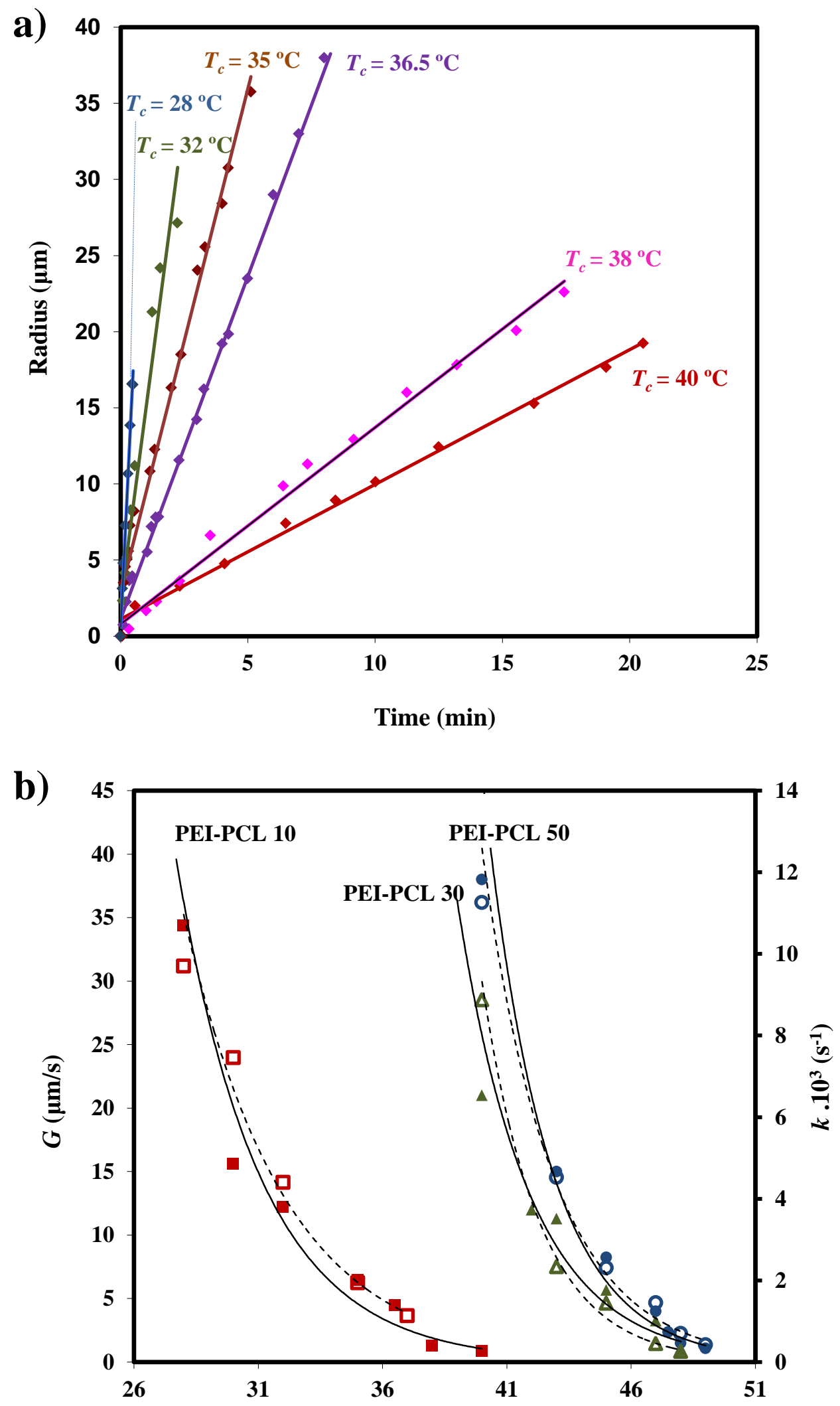

Temperature $\left({ }^{\circ} \mathrm{C}\right)$ 
a)
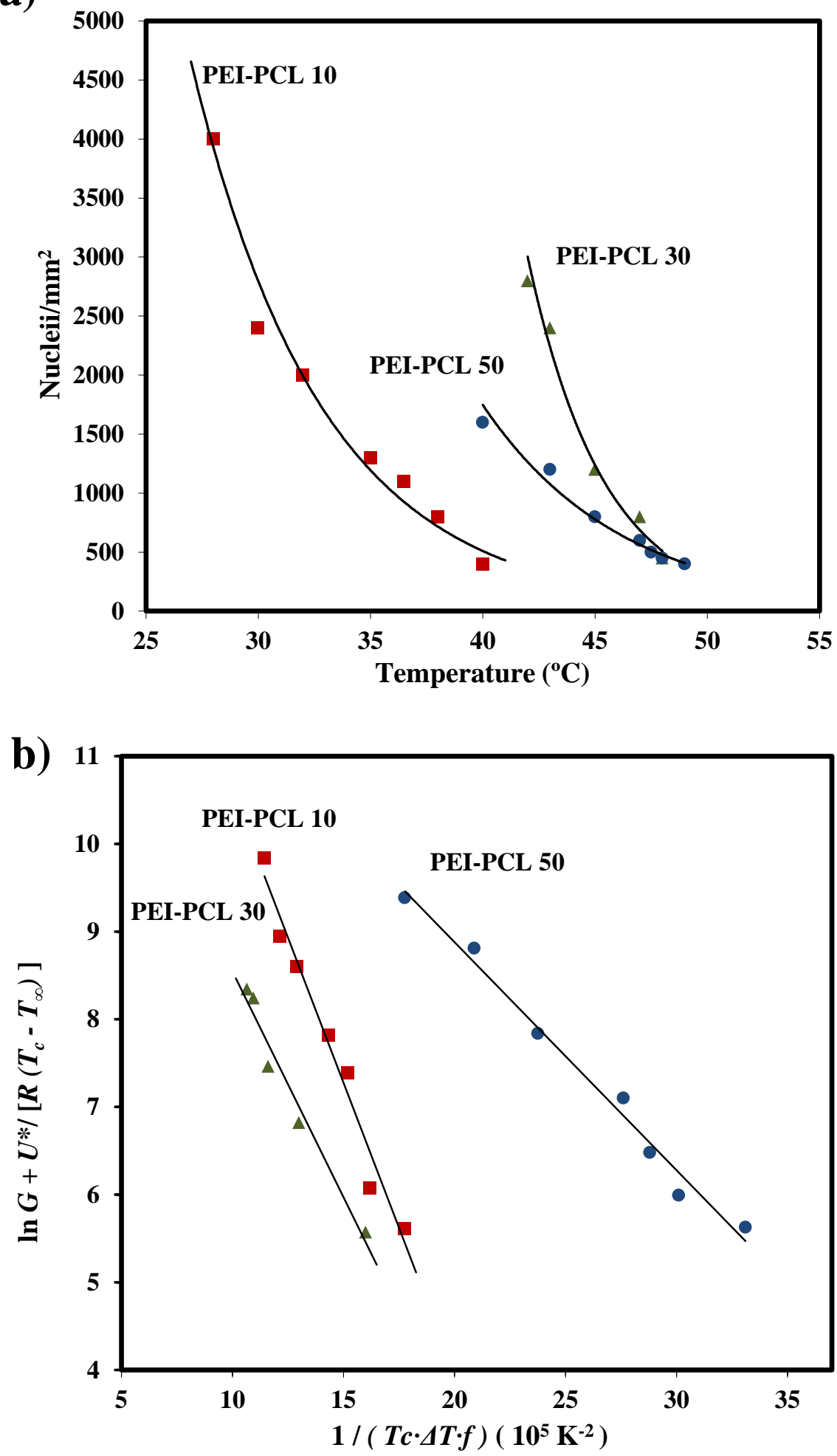

FIGURE 11 Díaz et al. 


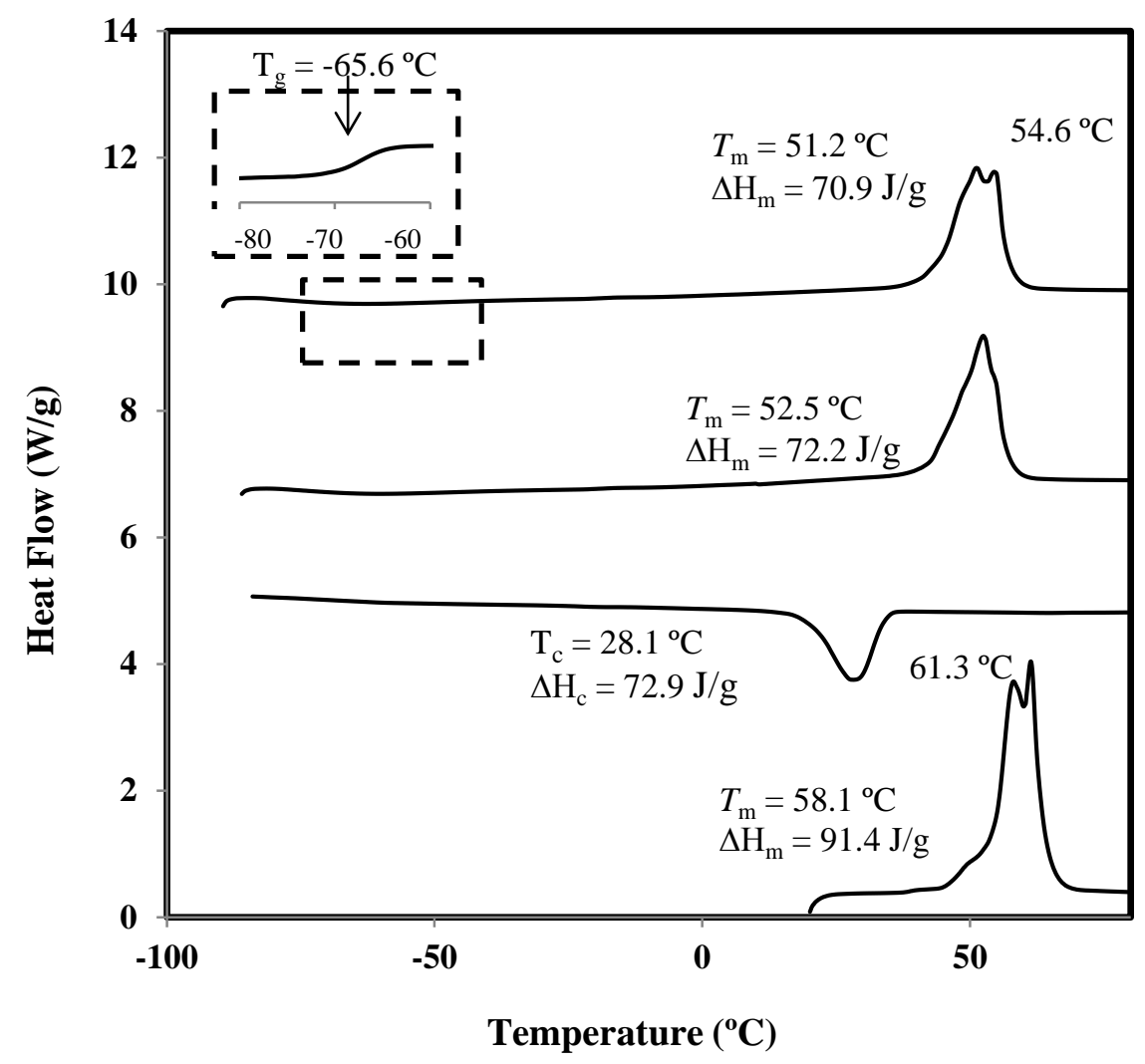

FIGURE 12 


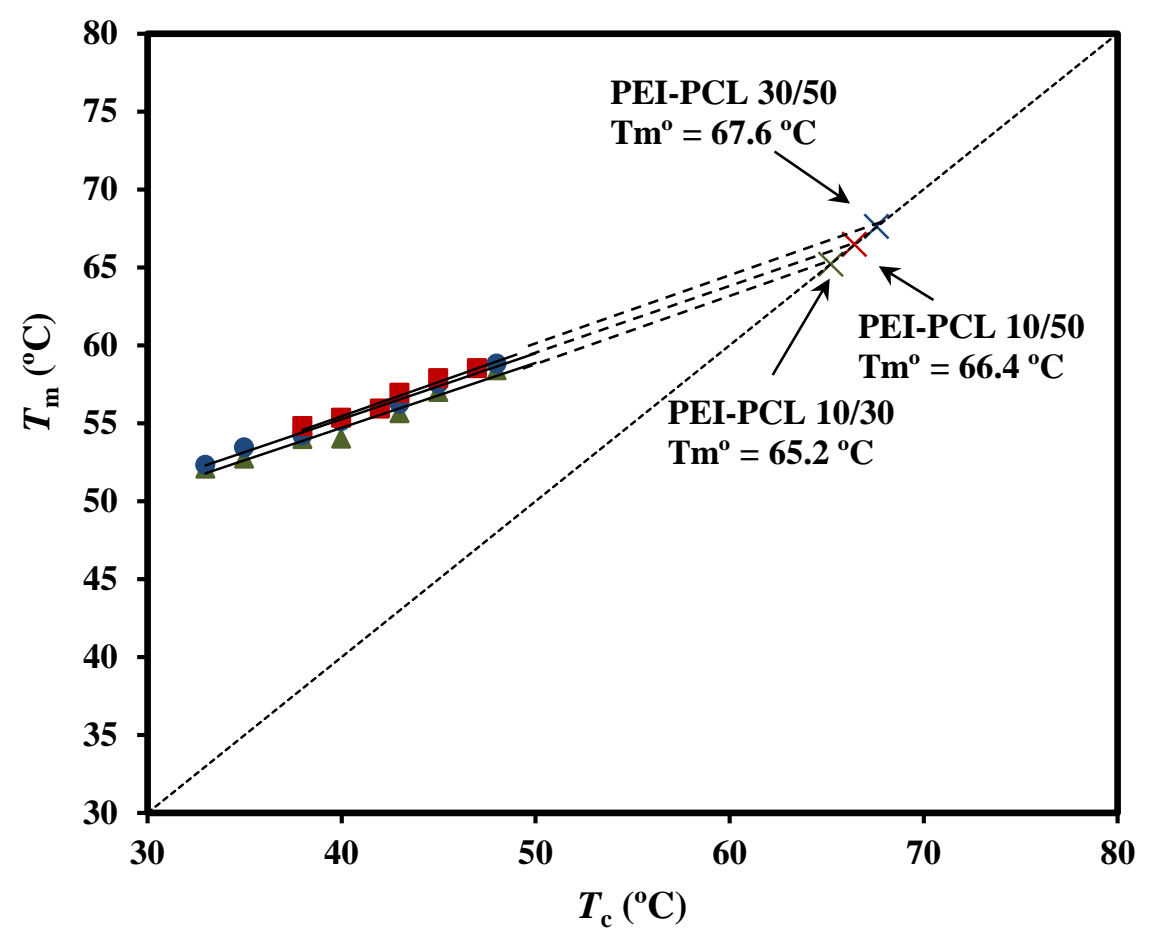

FIGURE 13

Díaz et al. 


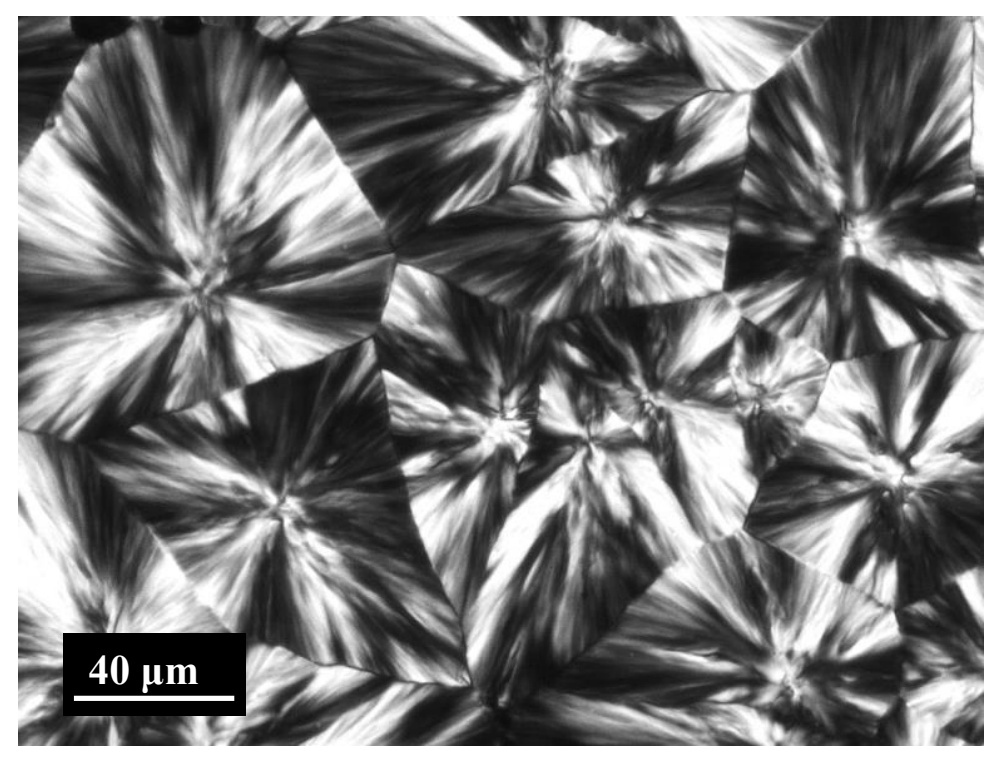

FIGURE 14 Díaz et al. 
a)

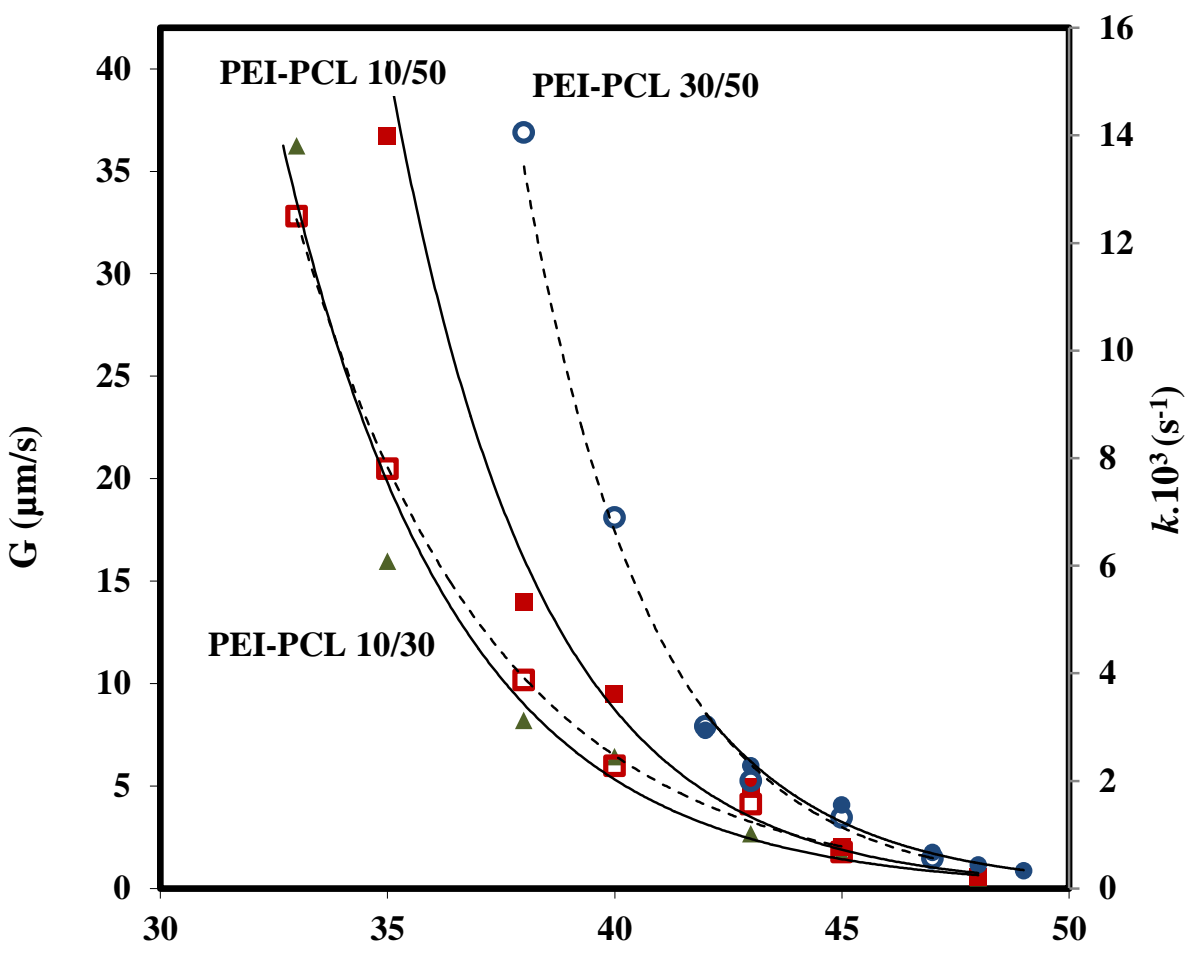

Temperature $\left({ }^{\circ} \mathrm{C}\right)$

b)

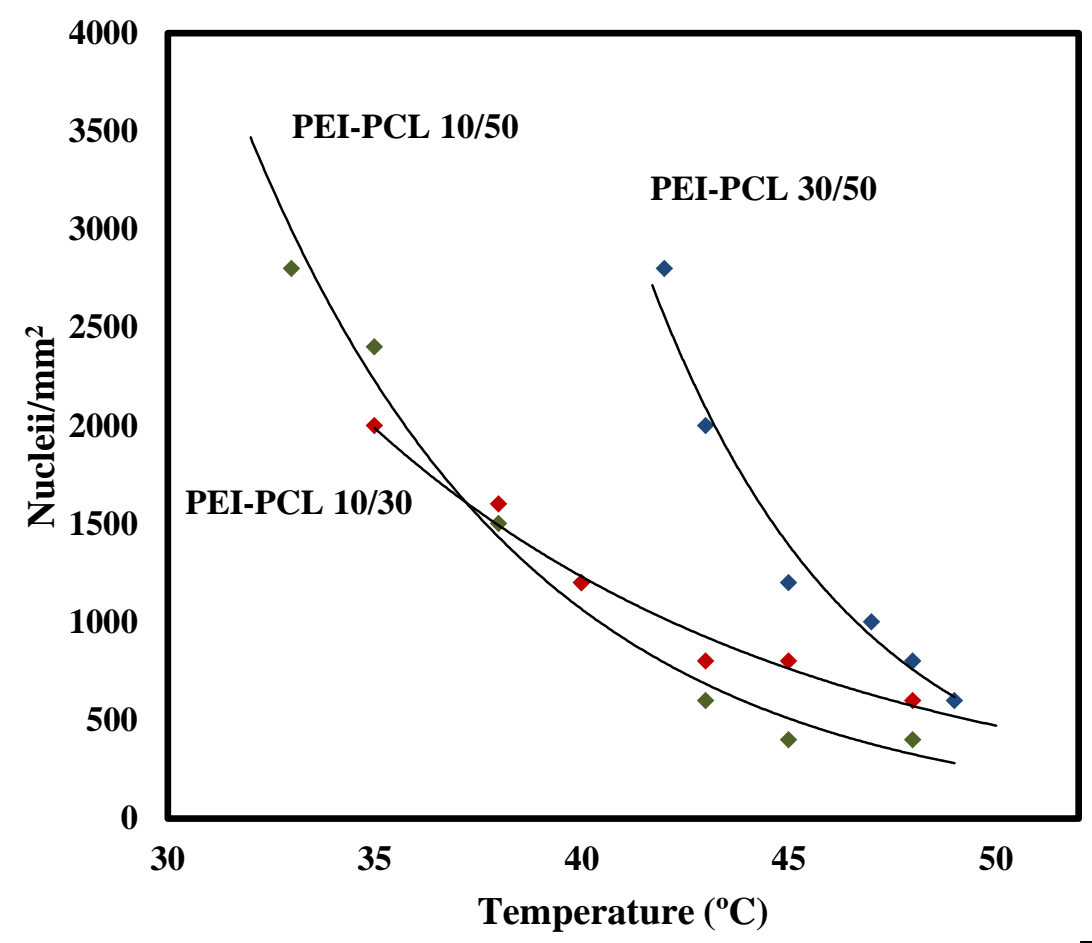

FIGURE 15

Díaz et al. 


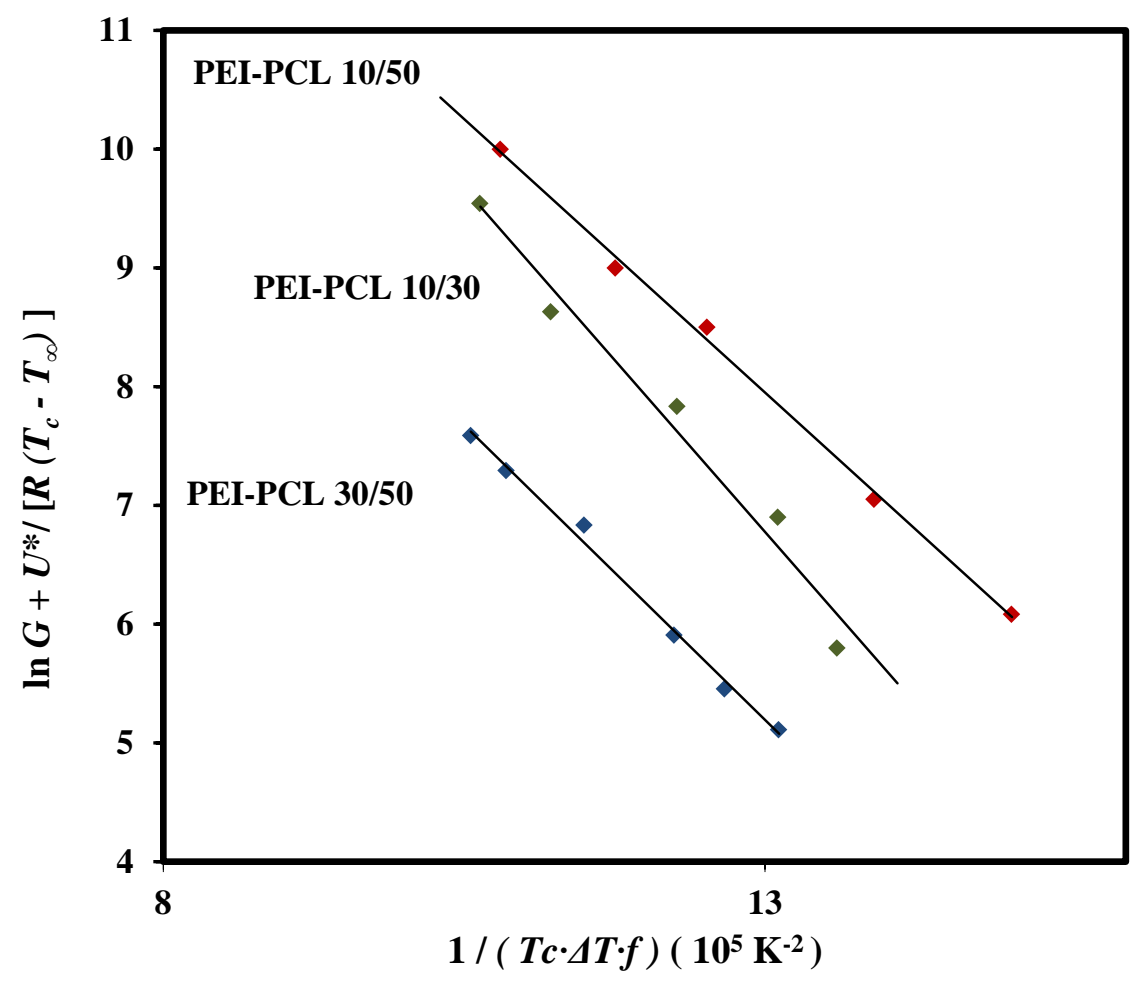

FIGURE 16

Díaz et al. 